\title{
Applicants' Perceptions of Selection Procedures and Decisions: A Critical Review and Agenda for the Future
}

\author{
Ann Marie Ryan \\ Michigan State University \\ Robert E. Ployhart \\ University of Maryland
}

\begin{abstract}
This review critically examines the literature from 1985 to 1999 on applicant perceptions of selection procedures. We organize our review around several key questions: What perceptions have been studied? What are determinants of perceptions? What are the consequences or outcomes associated with perceptions applicants hold? What theoretical frameworks are most useful in examining these perceptions? For each of these questions, we provide suggestions for key research directions. We conclude with a discussion of the practical implications of this line of research for those who design and administer selection processes. (C) 2000 Elsevier Science Inc. All rights reserved.
\end{abstract}

Over the past decade, there has been a surge of interest in studying how job applicants view the employee selection process. This research interest has been sparked by a number of forces. First, the greater competition for employees due to low unemployment rates (Nassar, 1999) has led organizational decision makers to think about how various components of selection processes might influence the attractiveness of the organization. Second, leading recruiting researchers, such as Rynes (1991, 1993), have called for better research on applicant perspectives. Third, researchers in the area of organizational justice have suggested and begun to explore the applicability of social justice theory concepts to applicant perceptions of selection methods (e.g., Gilliland, 1993). Fourth, the increasing diversity of the workforce (Cox, 1993; Jackson \& Associates, 1992) has led employers to be concerned that certain procedures might make an organization less attractive to qualified minority group members. In addition to examining racial differences in perceptions of selection processes, researchers interested in lessening the adverse impact of selection procedures have been interested in whether attitudes about

Direct all correspondence to: Ann Marie Ryan, Department of Psychology, Michigan State University, East Lansing, MI 48824-1117; Phone: (517) 353-8855; E-mail: ryanan@pilot.msu.edu. 
tests might account for some of the performance differences observed between minority and majority group members on certain selection methods.

The basic premise of research on applicant perceptions of selection processes and procedures has been that these perceptions affect how the applicant views the organization (i.e., the process sends a signal; Rynes, 1993), his or her decision to join the organization, and subsequent behaviors (e.g., future product/service purchases, recommendations to others). Thus, understanding when and why applicants have more or less favorable impressions of a selection process might increase the ability to influence those perceptions and related applicant attitudes and behavior.

In this paper, we provide a review of the research on applicant perceptions of selection processes. We use the terms perceptions and selection processes broadly so as to provide a comprehensive review. That is, we discuss literature related to any attitudes, affect, or cognitions an individual might have about the hiring process, with several exceptions. First, there is a great deal of research on the effects of affirmative action and specifically on preferential selection (e.g., Heilman \& Herlihy, 1984; Heilman, Lucas, \& Kaplow, 1990; Heilman, Simon, \& Repper, 1987). This research is relevant because it examines applicant perceptions of a particular characteristic of a selection process. However, as this is reviewed comprehensively elsewhere ( Kravitz et al., 1997; Turner \& Pratkanis, 1994), we do not review this area but simply note its relevance to the study of applicant perceptions of selection procedures. Second, elsewhere in this issue, a review is provided of the research on recruiter effects on applicant perceptions (Breaugh, 2000). Thus, we do not discuss how recruiter characteristics and recruitment materials affect applicant perceptions, although we do discuss perceptions of interviews as a selection procedure in contrast to other selection methods. Third, there is research on attitudes toward drug testing of current employees; we exclude this from our review and focus only on drug testing in selection contexts.

We have organized the review in the following manner. First, we provide a brief overview to orient the reader. We then present a tabular summary of the published empirical work in this area. There have also been numerous unpublished conference papers related to this topic and we discuss these in the text where relevant. We limit this review to the last 15 years for the sake of parsimony, but also because most work has occurred since that time. We discuss the table's contents and theoretical work in the area in terms of the following questions:

- What applicant perceptions have been studied? What should be studied?

- What are the determinants of applicant perceptions?

- What are the consequences of holding more positive or negative perceptions (i.e., to what outcomes have they been linked)? What moderates these relations?

- What theoretical frameworks have been presented? How well have they been applied? What other theoretical viewpoints need consideration? 
In each section, we include what we see as key research needs on the topic of applicant perceptions. We end with suggestions for new research directions and some practical implications.

\section{Overview of the Research Area}

Researchers have mentioned applicant perceptions of selection procedures as an avenue of inquiry for quite some time (e.g., Mosier, 1947). In the late 1980s and early 1990s, a number of book chapters and theoretical pieces appeared that suggested there was not enough attention being paid by researchers to the fact that selection involves two parties: the organization selects employees, but applicants also select-where they will apply and where they will work (e.g., Herriot, 1989; Rynes, 1991, 1993; Schuler, 1993). Although the recruiting research literature was certainly addressing what drives applicant decisions, it was not focused on the selection process as an element in those decisions. In particular, Rynes (1993) pointed out some key research needs in studying applicant perceptions that spurred other research.

Schmitt and Gilliland (1992) and Gilliland (1993) developed a model of how and why situational factors in the selection process influence perceptions of the fairness of the process and how these perceptions influence applicant attitudes and behaviors. Gilliland proposed that situational characteristics (e.g., test type, organization human resource policy, the behavior of human resource personnel) influence applicant perceptions of the procedural justice of the selection system. He noted that perceptions of the extent to which specific procedural rules (e.g., job relatedness, consistency of administration, priority of questions) are satisfied or violated are combined to form an overall evaluation of the fairness of the selection process. He also noted that an applicant's prior experiences with a selection process would influence this evaluation. Gilliland proposed that perceptions of distributive fairness (i.e., the fairness of either the test outcome or the hiring decision) are influenced by the distributive justice rules of equity, equality, and need, which in turn are influenced by such things as performance expectations and the salience of discrimination. Consistent with the justice literature, his model proposes an interaction of procedural and distributive rules in forming fairness perceptions of the process and of the outcome. Gilliland indicated that fairness perceptions should relate to outcomes such as job application decisions, test motivation, self-esteem, self-efficacy, endorsement of the company's products, job acceptance decisions, job satisfaction, and performance, among others. We refer the reader to his article for a comprehensive discussion of this model. Gilliland's conceptualization has served as the basis for a large number of the studies in the applicant perceptions literature.

Two other influential pieces that did not derive from Gilliland's conceptualization but can be seen as focusing on "justice-related" perceptions are Arvey and Sackett (1993) and Smither, Reilly, Millsap, Pearlman, and Stoffey (1993). Arvey and Sackett (1993) proposed a slightly different set of factors as influencing perceptions of fairness, some of which remain unexamined to date. Smither et al. (1993) looked specifically at job-relatedness, which is one of the justice rules 
in Gilliland's model, and developed a two-factor measure of it - face validity and perceived predictive validity - that has been widely used in subsequent research.

A second stream of applicant perceptions research comes from attempts to understand what drives performance on cognitive ability tests. Although research on this topic has led in many directions (e.g., understanding the nature of intelligence, examining effects of methods of testing and question variants), some has been directed specifically at how the perceptions of the test taker affect test performance. Although this was not the primary force behind its development, Arvey, Strickland, Drauden, and Martin's measure of test attitudes for use in selection contexts (Arvey, Strickland, Drauden, \& Martin, 1990) serves as a seminal piece in the applicant perceptions literature that follows this research trend. The factor accounting for the most variance in their measure was test-taker motivation, and they noted that motivational differences might account for some portion of racial differences in cognitive ability test scores. Subsequent researchers have used Arvey et al.'s measure to further examine this question (e.g., studies by Chan and colleagues).

Thus, there have been two major thrusts to the applicant perceptions literature: a focus on fairness and other characteristics of the selection methods as potential influences on applicant attraction to an organization (referencing Gilliland, 1993; Smither et al., 1993), and a focus on test-taker attitudes as an influence on how applicants perform in the selection process (referencing Arvey et al., 1990). Note that the former focuses on perceptions of procedures and decisions, while the latter focuses more on perceptions of one's own cognitions and behaviors while experiencing those procedures and decisions. We feel both streams of research are important for understanding what an applicant might think, feel, and do based on having participated in a selection process.

Table 1 provides a summary of published empirical studies on applicant perceptions conducted since 1985 . We chose to point out particular features of studies that relate to some key concerns in this research area. The second column - types of perceptions - addresses the question of what phenomena are being studied. The next three columns-procedures studied, timing of measurement, and type of sample-all focus on the generalizability of this area of research. We then chose to highlight "determinants" and "outcomes" of perceptions because the critical research questions are: 1) What leads to perceptions? and 2) Do these perceptions lead to any attitudes or behaviors of importance? Note that characterizing variables as "determinants" was somewhat finessed, as some authors clearly labeled non-manipulated variables as simply correlates, others manipulated such variables to indicate they were determinants, and in other cases causality was assumed. We mention variables studied that we feel deserve further consideration as potential determinants of reactions. Also, we note that some authors were interested in the perceptions or reactions of applicants as the dependent variable of interest, whereas others were interested in how these perceptions influenced other outcomes. We label perceptions of the job and organization as outcomes, although many researchers refer to these as "applicant reactions." In the table, we also note one or two key findings from each study, recognizing that this provides only a limited picture of the research. We urge the 


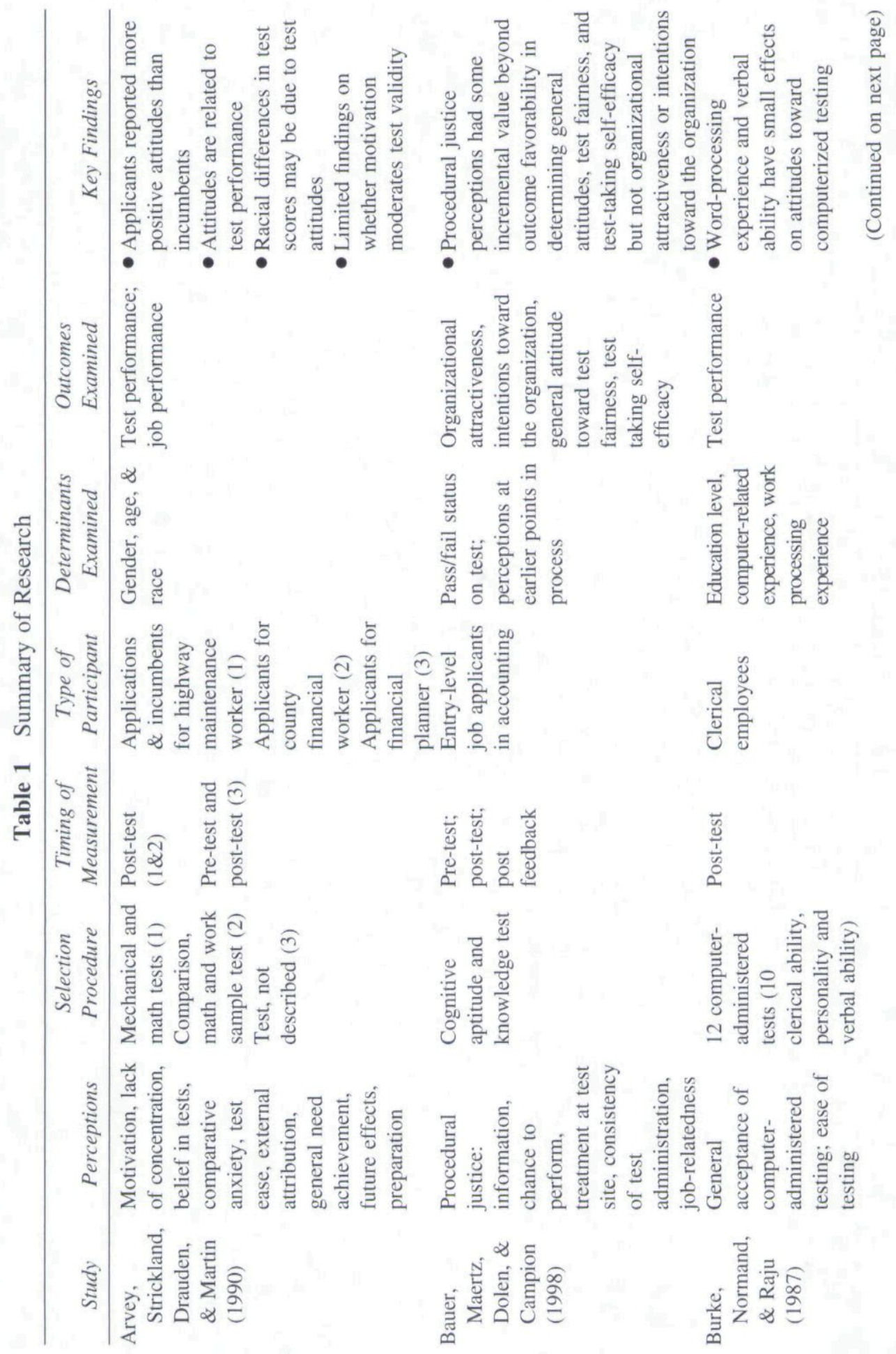




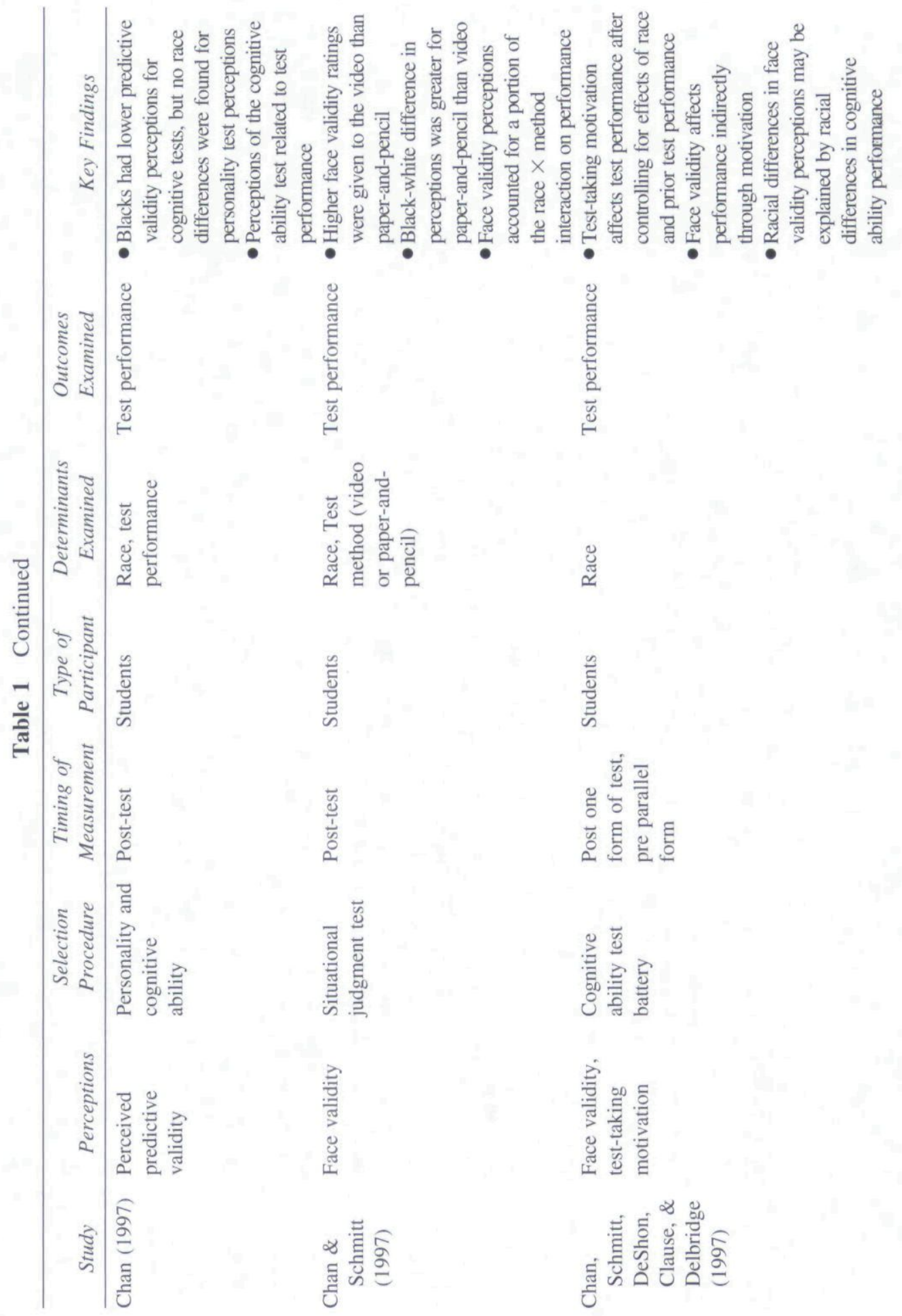



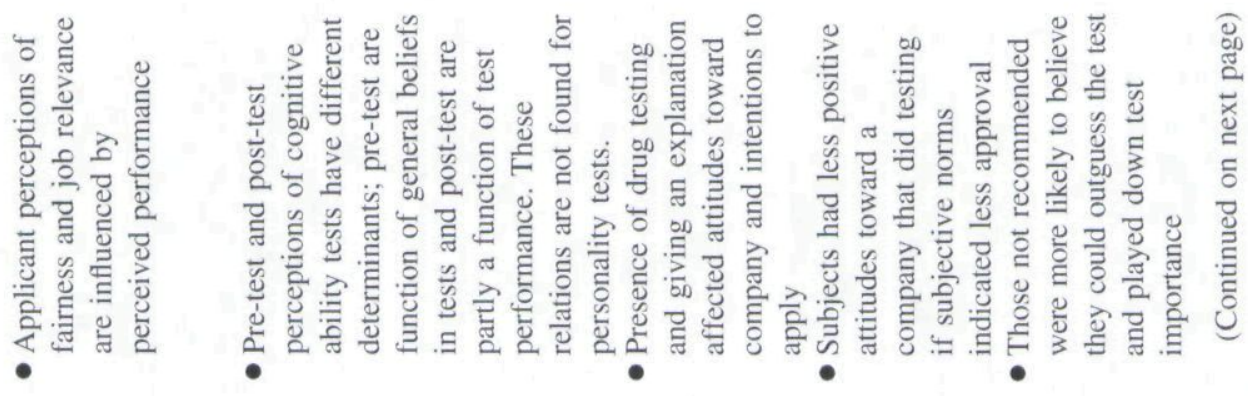

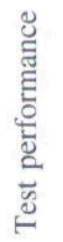

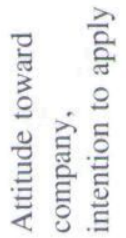

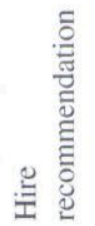

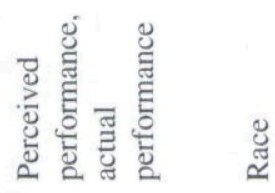

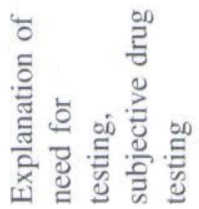

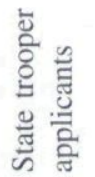

总

章

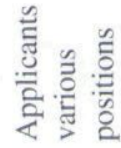

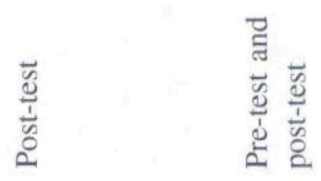

$\overrightarrow{3}$
$\frac{1}{1}$
0
0

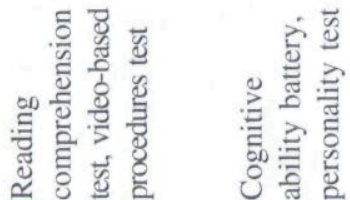

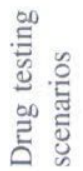

$\frac{\vec{s}}{3}$
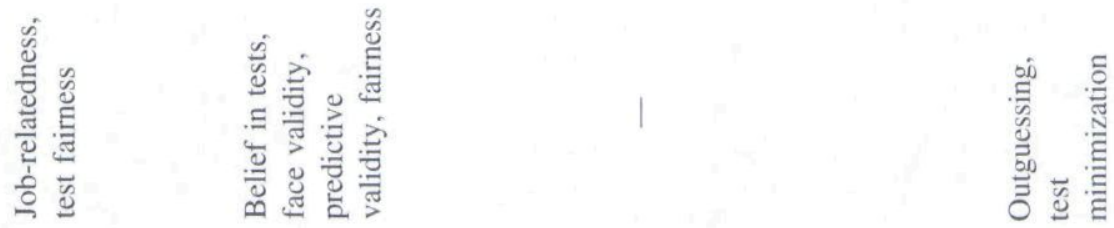

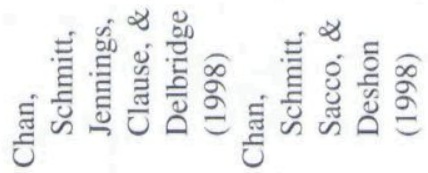
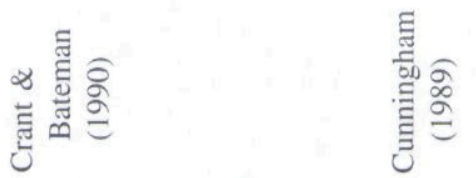


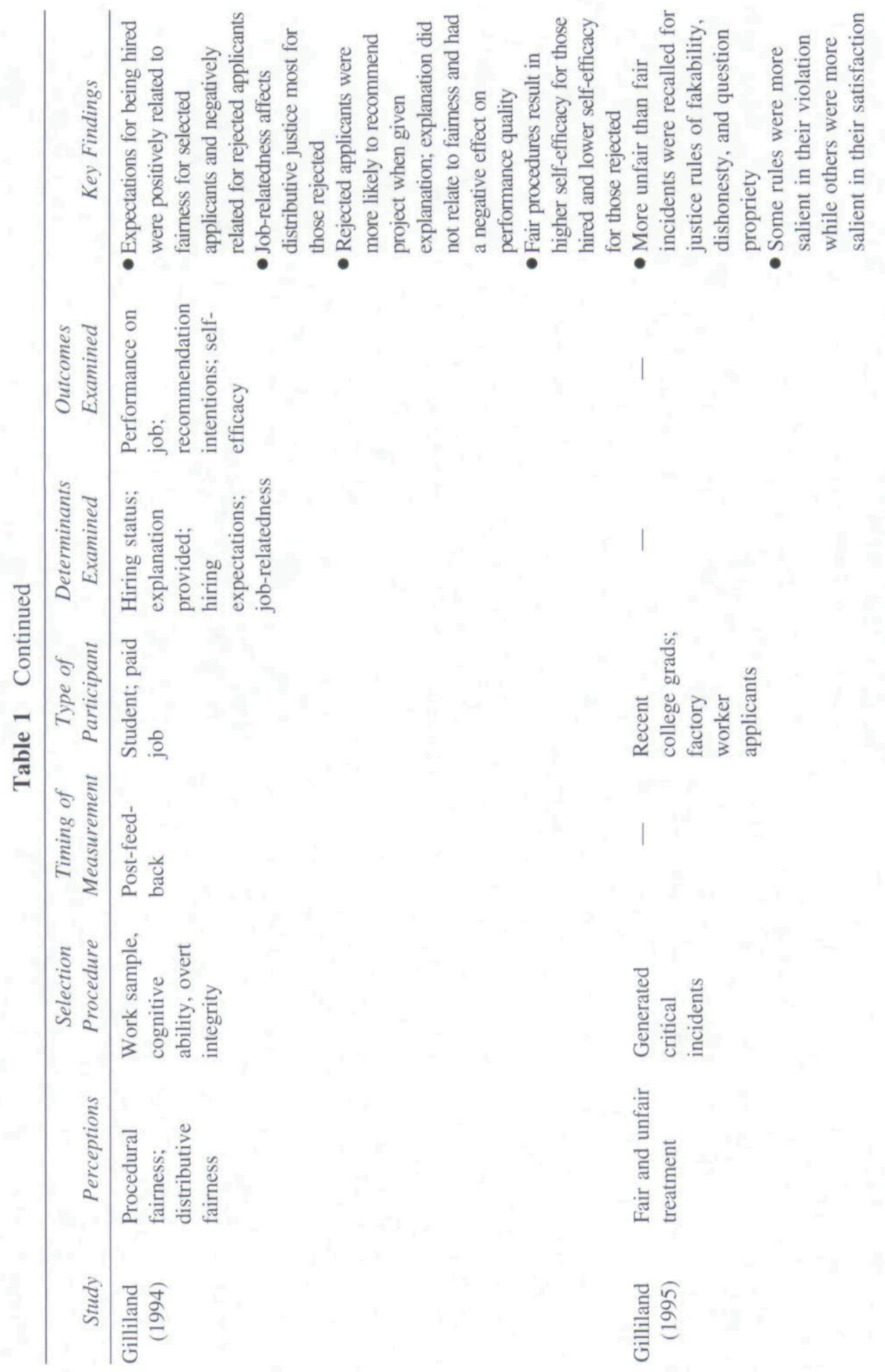




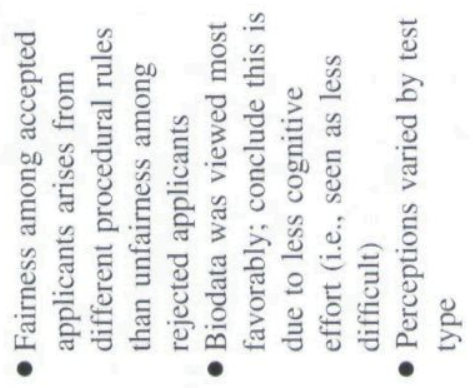

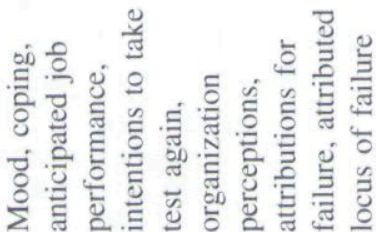

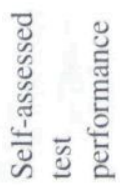

क्气

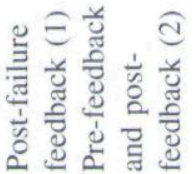

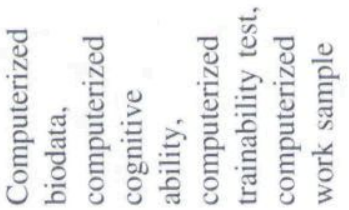

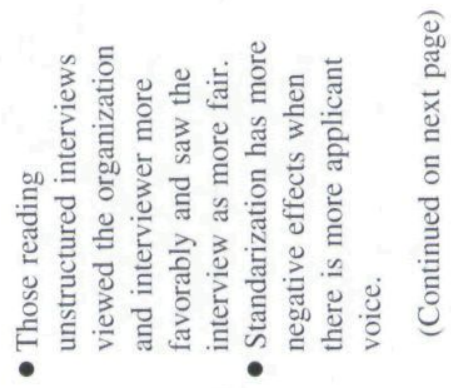

$\stackrel{0}{\underline{E}}$
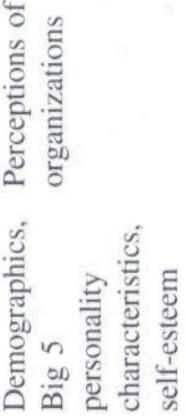

节

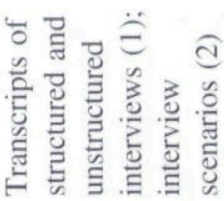

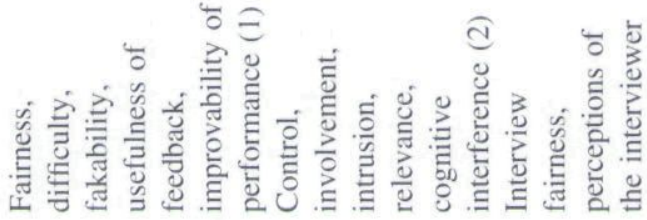

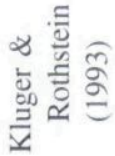

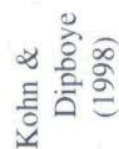




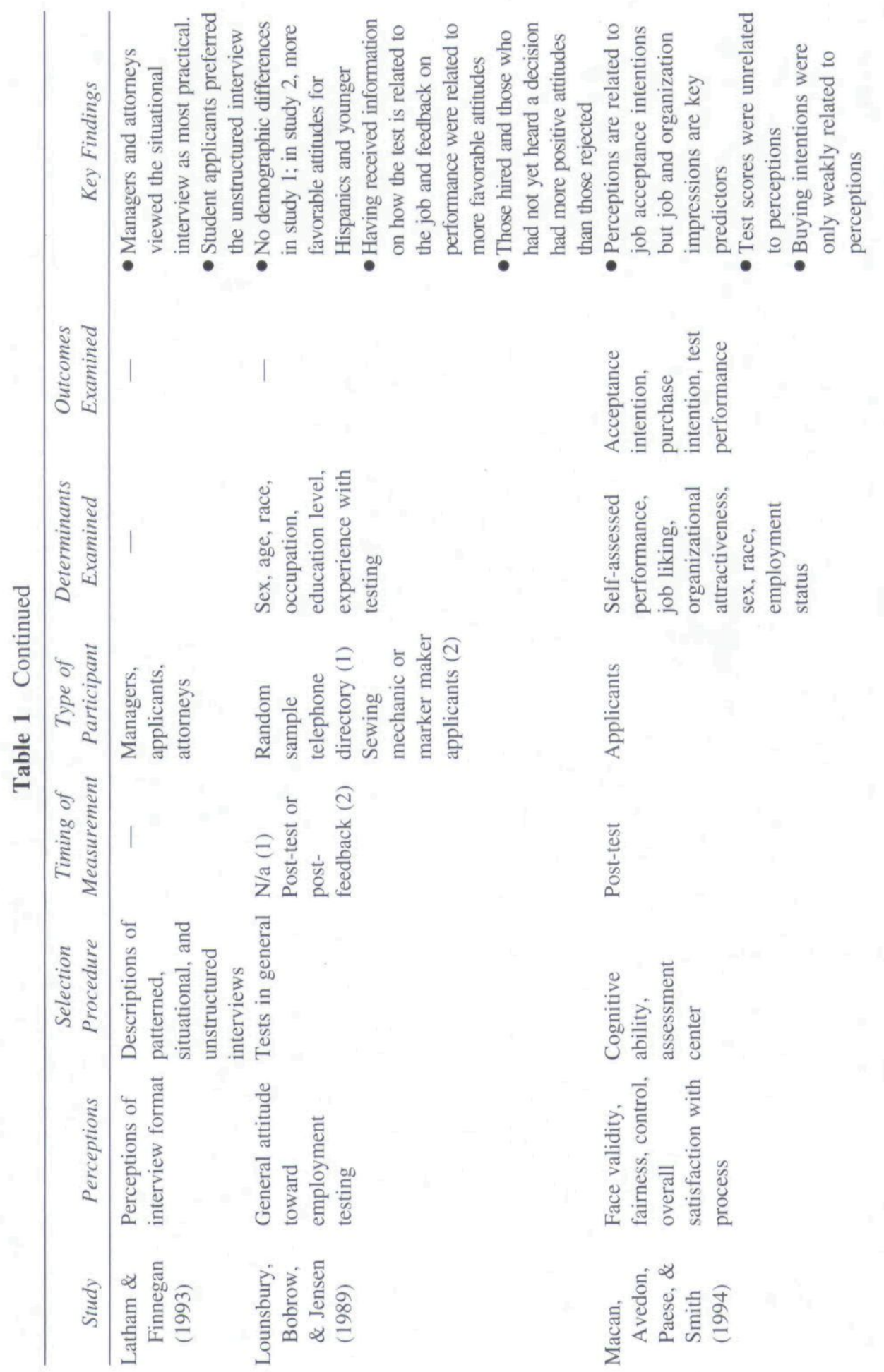




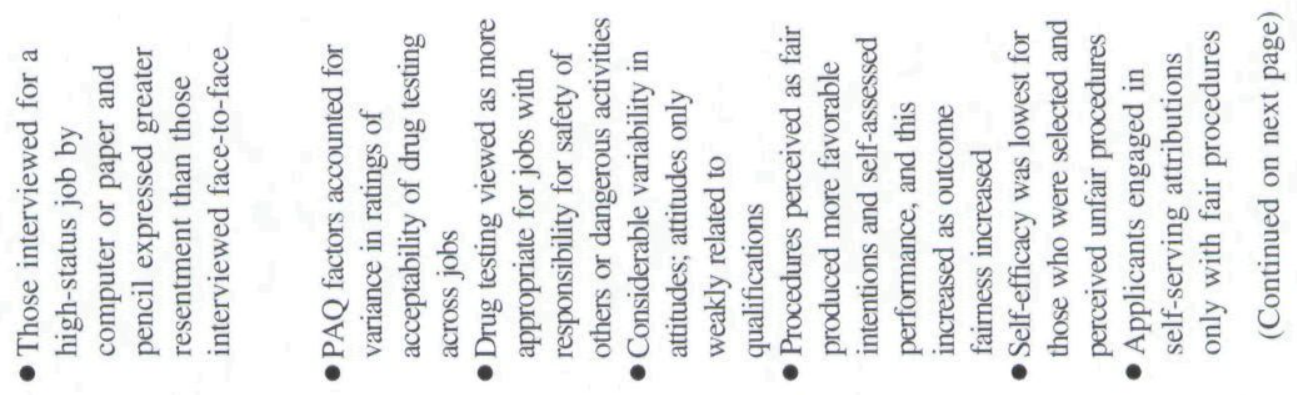

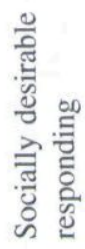

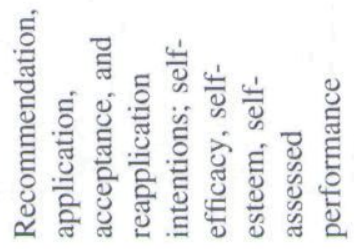

롱

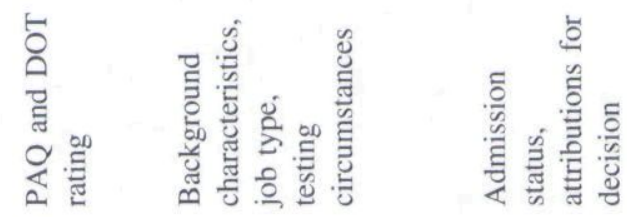

कै

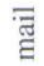

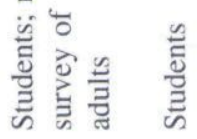

苞苍

के

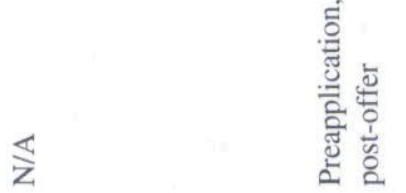

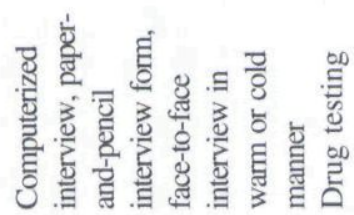
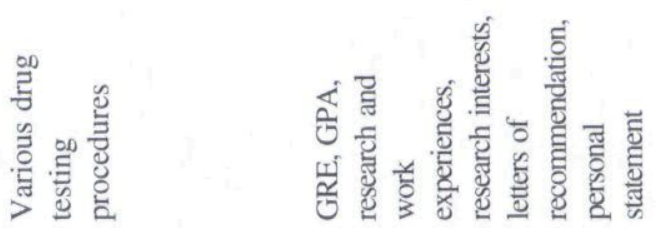

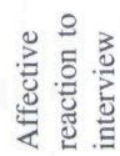
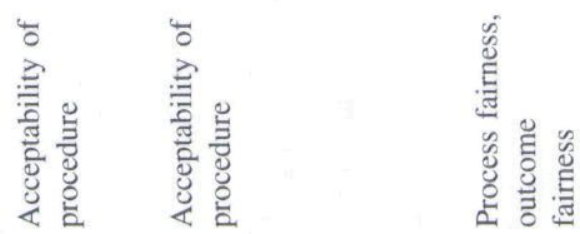

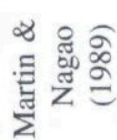

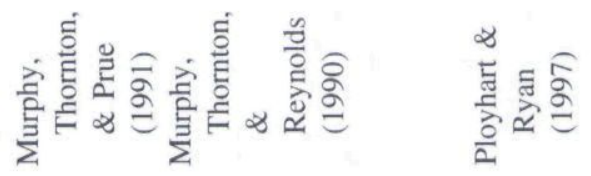




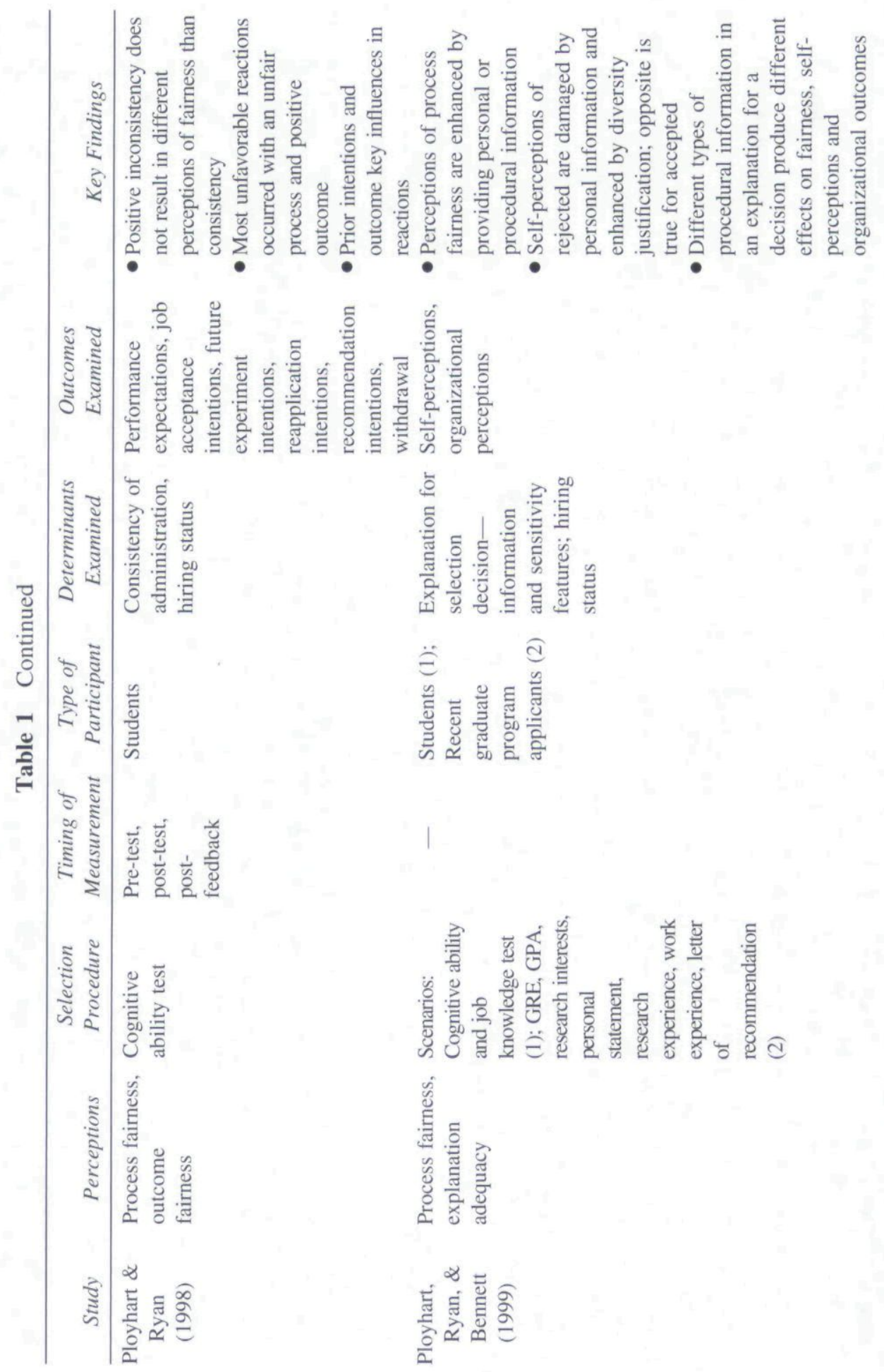




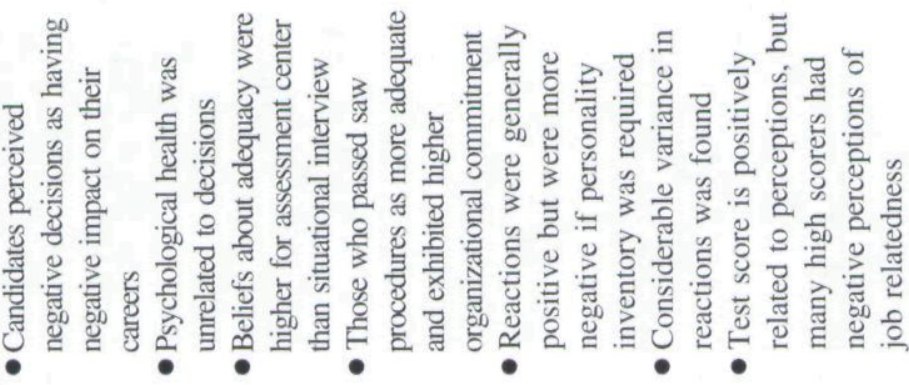

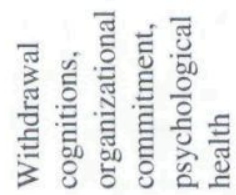

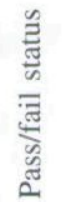

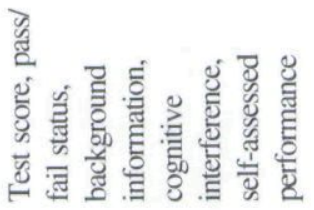

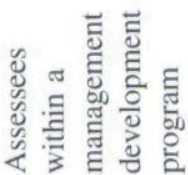

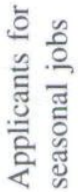

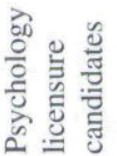

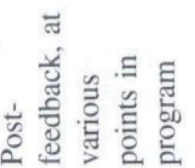

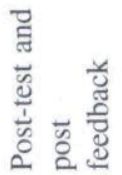

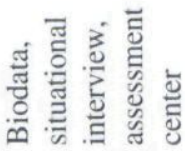

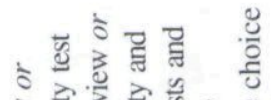

ปั.

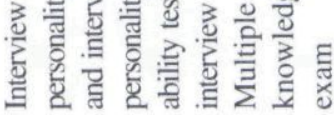

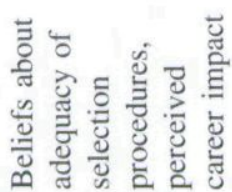

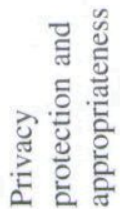

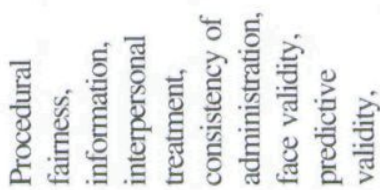

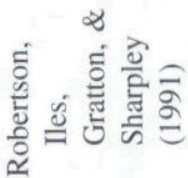

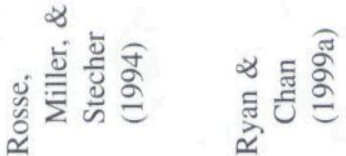




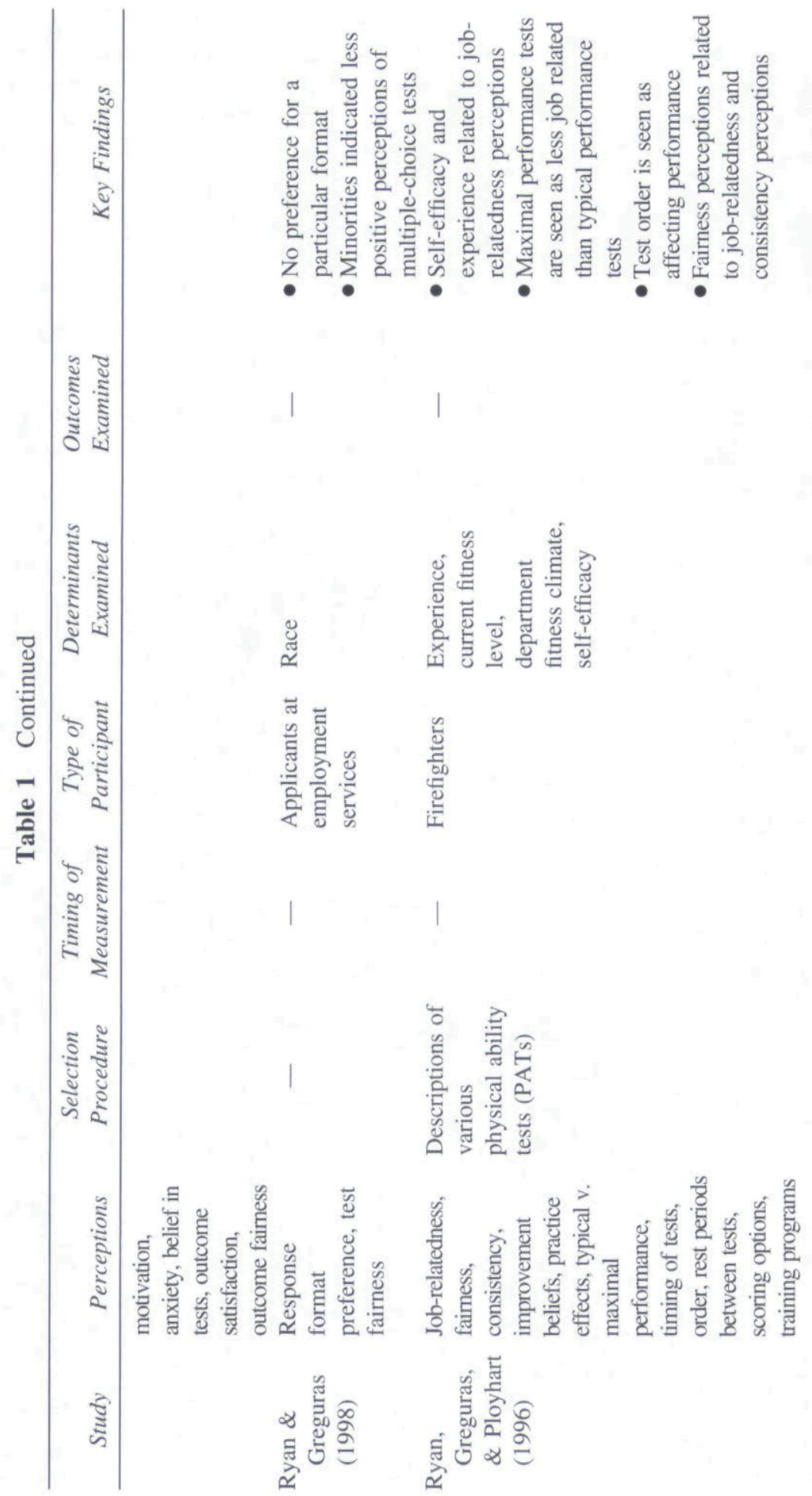




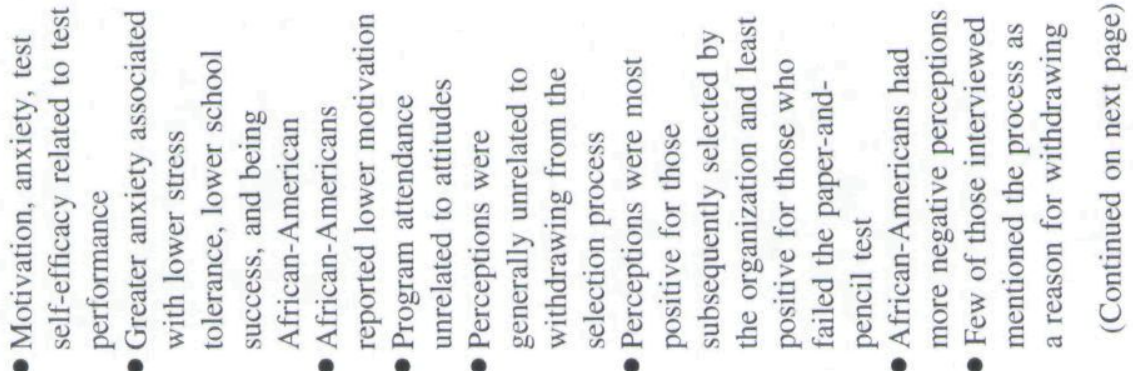

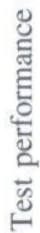
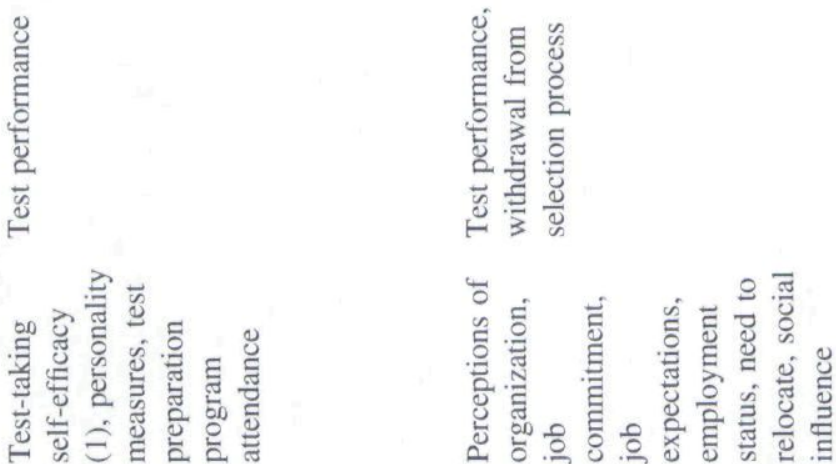

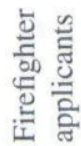

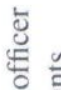

응 ․ㅡㅇ

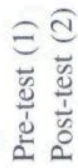

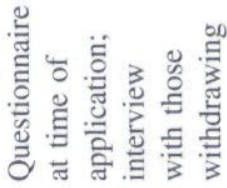

동

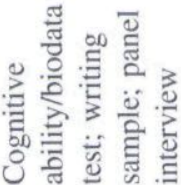

ลิ

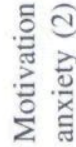

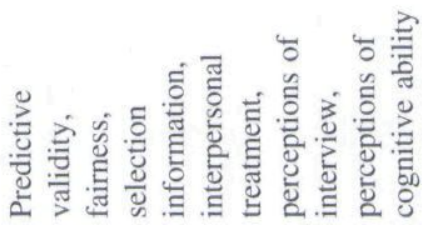

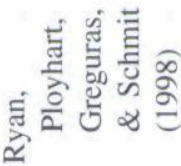

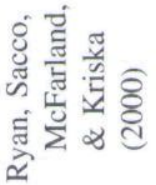




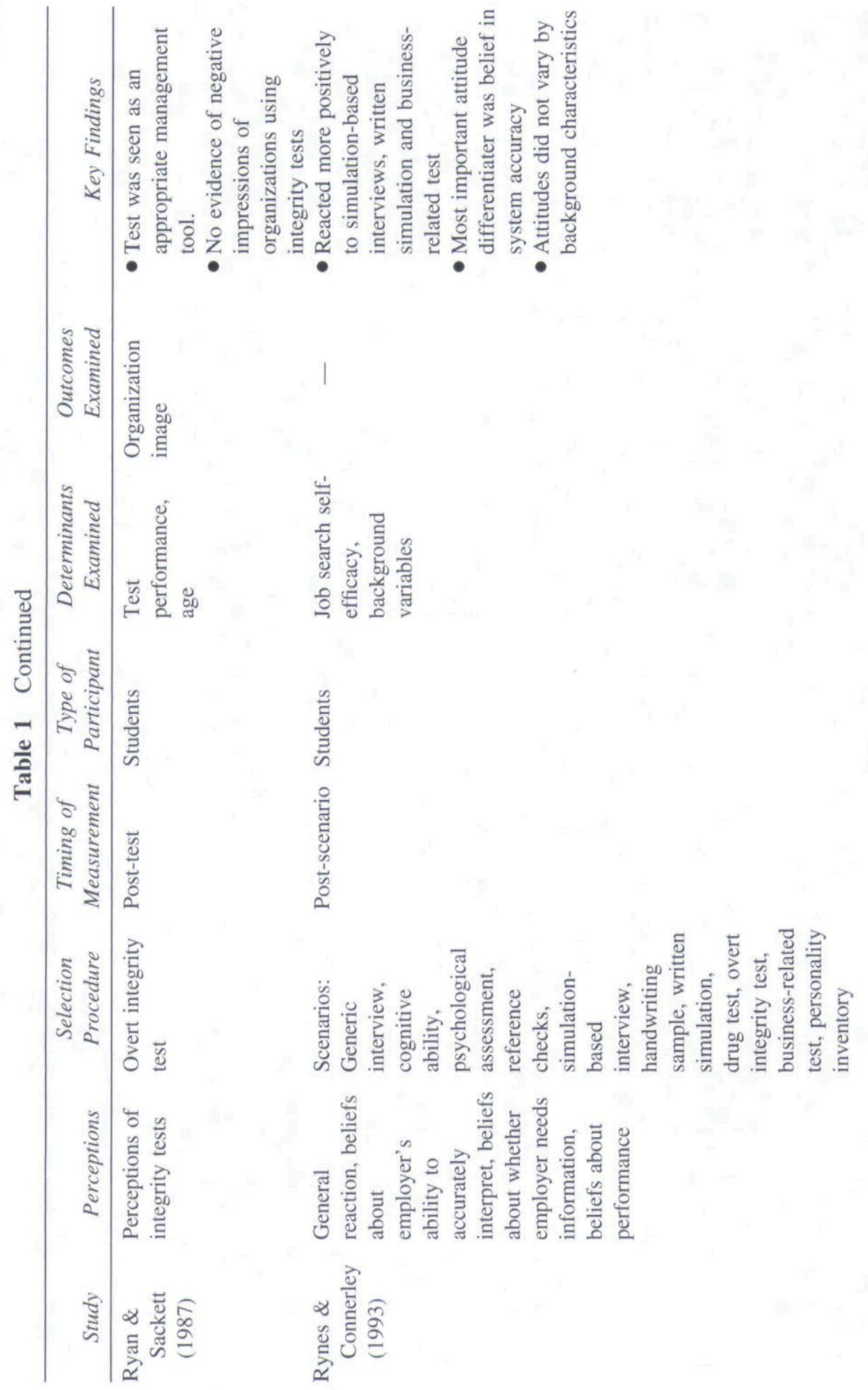



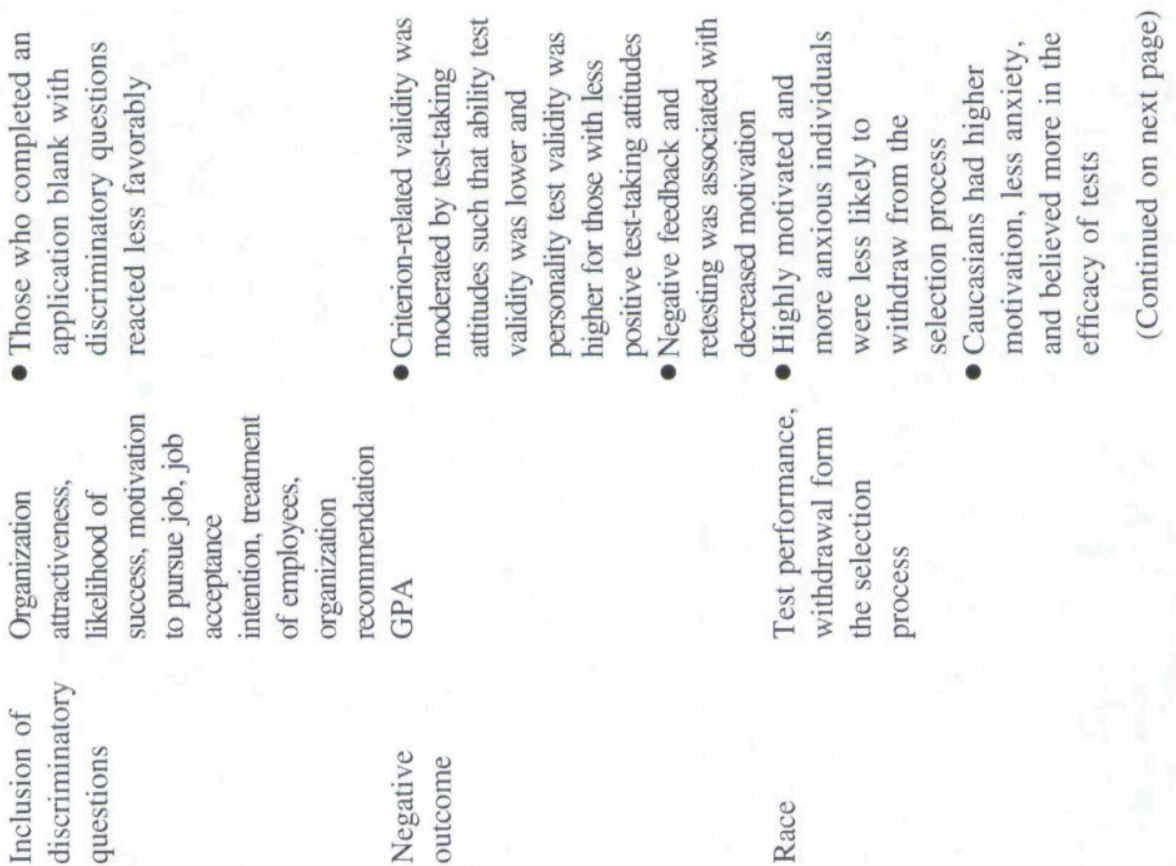

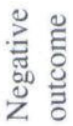

๕్ష

竎

苞

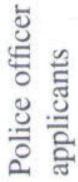

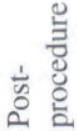

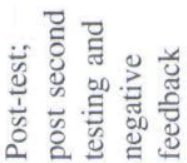

$\frac{\bar{s}}{\frac{5}{2}}$

哭

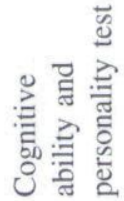

完䒿
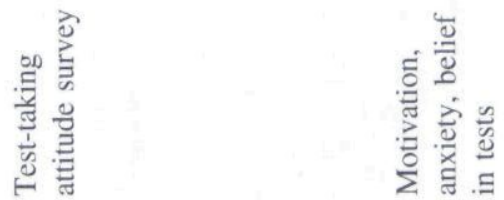

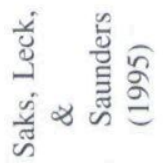

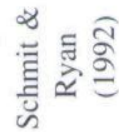

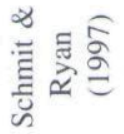




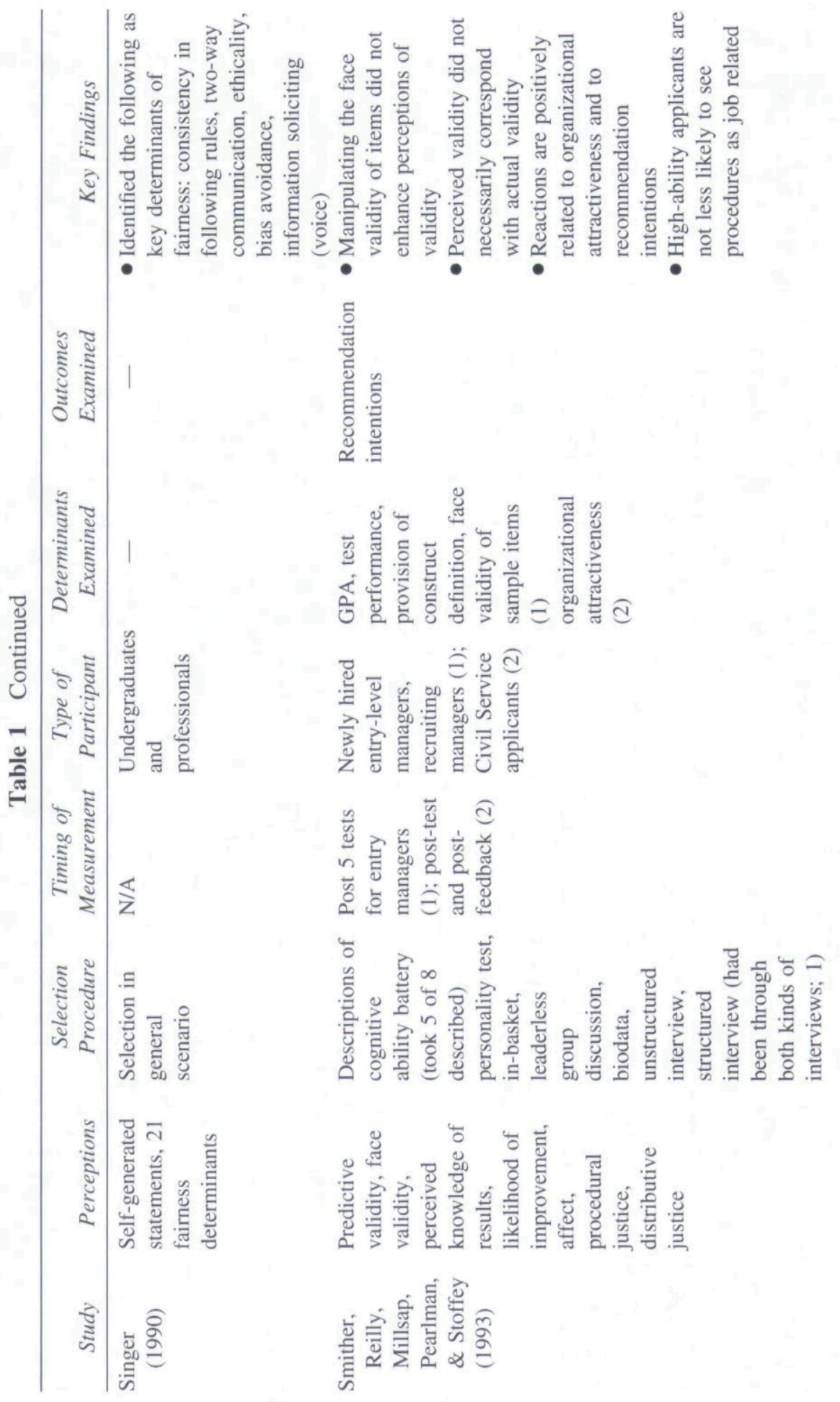

JOURNAL OF MANAGEMENT, VOL. 26, NO. 3, 2000 

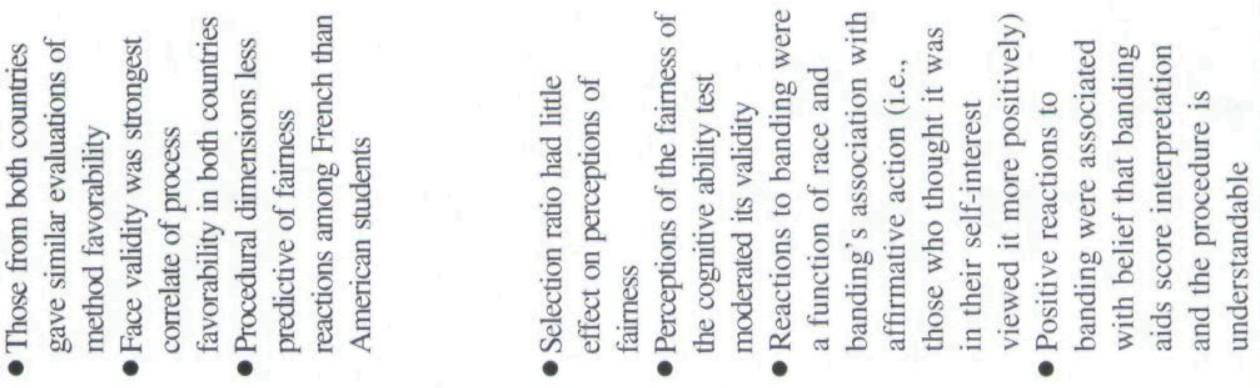

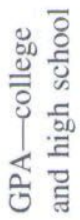
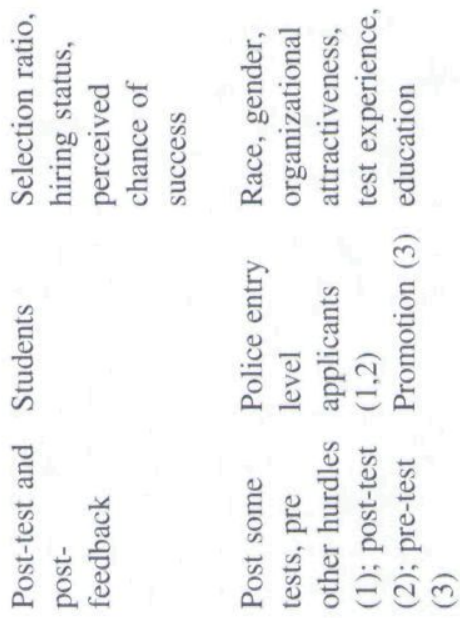

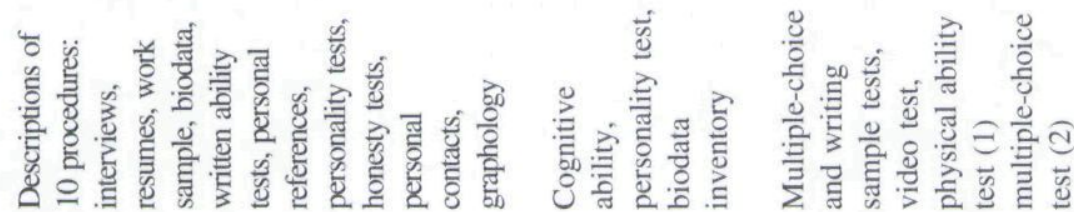
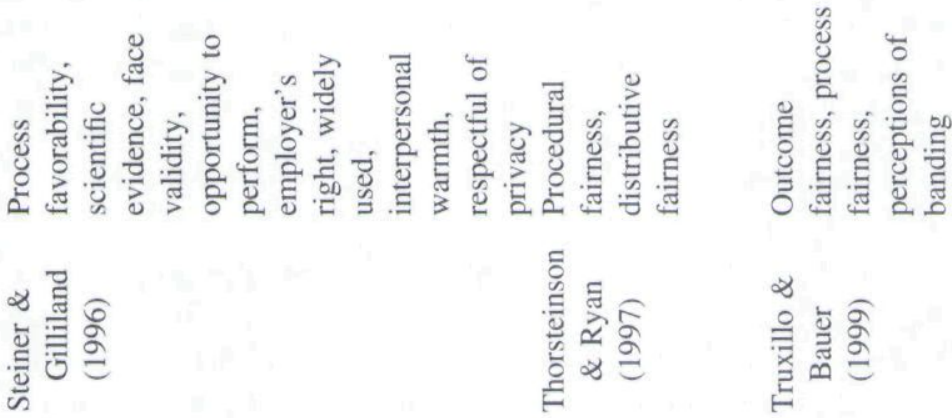
interested reader to refer to the primary work and to consider the table in light of its purpose: to provide a very broad summary. We now turn to discussing some specific questions that are addressed via the table

\section{What Applicant Perceptions Have Been Studied? What Should be Studied?}

The most commonly studied perceptions of applicants are perceptions of the validity or job-relatedness of the selection process, perceptions of the fairness of various aspects of the process and of the outcome of the process, and test-taking motivation. Not surprisingly, these derive directly from the seminal articles we mentioned earlier: Smither et al. (1993), Gilliland (1993), and Arvey et al. (1990). An examination of column 2 of Table 1 provides some examples of other perceptions studied. Rather than discussing each study, we offer the following general suggestions:

\section{Improve Perception Measurement}

One major concern with the research to date on applicant perceptions is the imprecision with which the constructs assessed are defined and the variability with which they are operationalized. This concern makes summarizing research difficult, as one cannot be certain if differences in findings are due to inadequate measurement or the assessment of truly different constructs. Insufficient work has been done on the reliability and validity of measures of applicant perceptions. We state this as researchers who are guilty ourselves of "using the scale most commonly used," rather than working toward improvement. For example, the factor structure of the Test Attitude Survey (Arvey et al., 1990) may not be what the developers proposed (Schmit \& Ryan, 1992). Another example would be the clarity and consistency of the referents in measures. Some items/scales are clearly related to a specific procedure or aspect of the selection process (Thorsteinson \& Ryan, 1997), while other items/scales relate to the entire process (Gilliland, 1994; Ployhart, Ryan, \& Bennett, 1999). Some items/scales refer to one's own outcome (Gilliland, 1994), while others refer to the fairness of outcomes in general (Truxillo \& Bauer, 1999). Across studies, process or procedural fairness has been assessed with different measures (e.g., Gilliland, 1994; Macan, Avedon, Paese, \& Smith, 1994; Truxillo \& Bauer, 1999). Although there has been some work on scale development (e.g., Gilliland \& Honig, 1994), more is needed. However, first construct definitions must be clarified. For example, interpersonal treatment sometimes refers to the personal or impersonal nature of the process whereas other times it refers to the behavior of administrators.

\section{Clarify How Test-Taking Attitudes Relate to Fairness Perceptions by Conducting Studies that Integrate the Two Streams of Research}

A better integration of the research on test attitudes and on fairness is needed to advance understanding. Although the work of Chan and colleagues (Chan, Schmitt, Sacco, \& DeShon, 1998) does some linking, this research has focused on only one or two concepts from each line of research. Thus, we do not really know 
if those who are more anxious view procedures as more unfair, if those who are highly motivated have different perceptions of the fairness of a rejection decision than those with low motivation, or if general beliefs about testing are a greater determinant of perceptions of the fairness of a procedure than characteristics of the procedure and selection situation itself. Note that many test-taking attitude measures are perceptions of oneself in the selection situation (i.e., are you motivated, anxious) whereas justice related perceptions are typically about the procedure or process (i.e., is this test a fair method of hiring). One would expect these two types of perceptions to relate. Indeed, Chan et al. (1997) demonstrated that the effects of face validity (a procedural justice perception) on test performance are fully mediated by motivation. However, Ryan and Chan (1999a) did not find attitudes of licensure candidates (e.g., motivation, anxiety) to add to the prediction of post-feedback process fairness above and beyond pre-feedback process fairness and justice rules.

In general, applicant perceptions research lacks a nominological net-we do not have theoretical or empirical work that provides a broad enough picture of how these various types of perceptions might be expected to relate. (This does not imply there is no theory; as we noted earlier, the expected relations between justice related perceptions have been explicated by Gilliland, 1993.)

\section{Consider Measuring other Perceptions}

Although understanding how an applicant's motivation or perceptions of fairness influences his or her attitudes and behavior is important, researchers may be ignoring other perceptions with important outcomes. For example, Cunningham (1989) measured "outguessing." For many noncognitive measures, issues like perceived fakability may affect applicant behavior. Perceived ease or difficulty of a selection process has been suggested as having effects (e.g., Kluger \& Rothstein, 1993) but is not routinely incorporated in this line of research. Another suggestion is "procedural pain" (Ball, Trevino, \& Sims, 1993) or the extent to which a negative state such as embarrassment, humiliation, or stress is caused by a procedure, with the privacy of the process and outcome being important determinants of procedural pain. In selection settings where an applicant is relatively anonymous to other applicants, this may not be much of an issue; however, it may be much more important in promotion contexts or very public selection processes (e.g., civil service jobs, university administrators). Other perceptions that may have relevance are the order of testing, whether procedures are timed, the methods of scoring, and other administrative issues (Ryan, Greguras, \& Ployhart, 1996).

Ryan and Greguras (1998) noted that one limitation of a focus on fairness perceptions is that it ignores the fact that preference is a different concept from fairness. That is, there is research in the educational arena to show that individuals often prefer methods such as multiple choice testing while indicating they are less valid and less fair than other methods (e.g., essay, recall) (Bridgeman, 1992; Nield \& Wintre, 1986; Zeidner, 1987). To fully understand how an applicant reacts to a selection process, we need to consider perceptions other than just fairness as possible influences on behavior. 


\section{What are the Determinants of Applicant Perceptions?}

Of particular interest is what researchers have seen as the causes and correlates of various applicant perceptions. One difficulty in summarizing this portion of Table 1 is that while some studies treat certain variables as correlates or potential antecedents of perceptions of selection processes (e.g., organizational attractiveness, self-efficacy; Macan et al., 1994; Ryan, Ployhart, Greguras, \& Schmit, 1998; Truxillo \& Bauer, 1999), others see these same variables as potential outcomes of perceptions (e.g., Bauer, Maertz, Dolen, \& Campion, 1998; Ployhart, Ryan, \& Bennett, 1999). Such inferences may be appropriate when you have measurement at multiple points in time (as in Bauer et al., 1998); however, the current state of the literature indicates a lack of a clear consensus on what causes or is caused by perceptions. Also, only about half of the studies listed in Table 1 examined determinant-perception links-many researchers have not focused on what determines perceptions.

What are the key determinants of applicant perceptions? Table 1 indicates that perceptions of procedures (e.g., fairness, job-relatedness) appear to be influenced by type of procedure (both the construct assessed (i.e., cognitive ability, personality) and the method of assessment (video, paper and pencil)), selfassessed performance, type of job, information provided about the procedure, and, in some cases for some procedures, race of the applicant. A number of studies have suggested that perceptions of the fulfillment of justice rules (e.g., consistency of administration) determine perceptions of the fairness of the process, in keeping with Gilliland's model. We are reluctant to consider these as strongly supported relations in the selection context, despite their solid theoretical grounding in social justice theory, simply because few studies have actually manipulated these justice rules to see if they influence (rather than just correlate with) perceptions of the fairness of selection procedures (exceptions would be Ployhart \& Ryan, 1998, which manipulated consistency of administration, and Smither et al., 1993, which manipulated face validity).

We noted earlier that there are two streams of research, and the preceding paragraph speaks only to what determines perceptions of selection procedures. Prior performance history and race (for cognitive ability tests) appear to influence test-taking attitudes. Less research has focused on determinants of test-taking attitudes, most likely because extensive literature on topics like cognitive interference with test performance (Sarason, Pierce, \& Sarason, 1996) and recent work on stereotype threat (Steele \& Aronson, 1995) is seen as addressing determinants.

We also note that many of these determinants may also be moderators of the link between other determinants and perceptions or between perceptions and behavior (e.g., perceptions relate to applicant behavior for unattractive but not for highly attractive organizations). For example, Gilliland (1994) found that hiring expectations influenced the relation between hiring status and fairness perceptions. Because of the lack of clarity in empirical work on the exact role of these variables and inattention to the timing of measurement, we currently have little beyond some interesting correlational findings for many variables. 
Based on the findings of studies summarized in the table, we offer the following observations:

1: Whether applicants are accepted or rejected clearly influences perceptions; studies that examine perceptions absent feedback on the selection decision cannot be interpreted similarly to those measuring perceptions post-decision.

The most researched "cause" of perceptions is the outcome of the process itself. That is, whether or not one receives a favorable outcome (hired or not) is seen as a major influence. It is clear that the outcome received by an applicant can influence perceptions (e.g., Arvey et al., 1990; Bauer et al., 1998; Chan, 1997; Chan et al., 1998b; Cunningham, 1989; Ployhart \& Ryan, 1997, 1998; Robertson, Iles, Gratton, \& Sharpley, 1991; Ryan \& Chan, 1999a; Ryan et al., 1998; Ryan, Sacco, McFarland, \& Kriska, 2000), and this is consistent with basic research on justice issues (e.g., Greenberg, 1987). Yet many studies have examined reactions post-test, absent feedback. Simply studying how test scores relate to perceptions assessed pre feedback is not sufficient, as in many cases individuals do not self-assess performance well. Indeed, test scores have not always been found to relate to perceptions (e.g., Macan et al., 1994; Whitney, Diaz, Minneghino, \& Powers, 1998).

Studies of post-test perceptions may be helpful-these perceptions may relate to behaviors exhibited by applicants during later stages of the process prior to the organization's decision (e.g., withdrawal behavior). However, these behaviors may not be the focal ones of interest. As Greenberg (1986) noted in discussing performance appraisal research, "researchers and theorists should not allow distributive factors to get lost in the shadow of the recent attention paid to procedural determinants of fairness." (p. 342). It seems that this has occurred to some extent in the applicant perceptions literature.

2: All procedures of the same "type" (e.g., personality tests) are not the same, nor are procedures of different types viewed consistently.

Initial research comparing perceptions of different types of procedures (e.g., Kluger \& Rothstein, 1993; Kravitz, Stinson, \& Chavez, 1994; Rynes \& Connerley, 1993) has indicated that mean differences exist between perceptions of different types of tests (e.g., the job-relatedness of biodata and cognitive ability), but there is considerable variability in perceptions. As Ryan and Greguras (1998) noted, the face validity and fairness of specific procedures are not universally shared perceptions. Researchers have also found that although applicants may have general perceptions of a category of procedures (e.g., interviews), they also make distinctions within category. For example, Ryan, Greguras, and Ployhart (1996) noted considerable variability in reactions to different types of physical ability tests for the same job that assess the same abilities. Chan and Schmitt (1997) found differences in face validity perceptions for video and paper-andpencil versions of the same situational judgment test. Whitney et al. (1998) found differences in some perceptions of overt versus personality based integrity tests.

In studying perceptions of different procedures, there is a need to clarify what procedure characteristics give rise to perceptions (Brutus \& Ryan, 1998). 
For example, how does the method of assessing a construct affect perceptions (Chan \& Schmitt, 1997; Ryan \& Greguras, 1998; Shotland \& Alliger, 1999)? Does the transparency of an assessed construct affect perceptions? Does the ease with which one can self-assess performance affect perceptions (Fredriksen \& Collins, 1989)? Does the ability (or perceived ability) to prepare for a procedure affect perceptions (Ryan \& Chan, 1999b)? Do physical features (e.g., how "slick" materials look, test length, room in which an interview is conducted) affect perceptions? Does the level of structure in an interview affect perceptions (e.g., Gilliland \& Steiner, 1999)? Educational researchers interested in examinee perceptions (e.g., Nevo, 1992, 1995) have examined such features as the convenience of the answer sheet and the test's physical attractiveness. All of these distinctions remain to be researched in the selection context. We caution against a piecemeal approach to a study of procedure characteristics, and we advocate the development of models of antecedents that clarify expected relations. At the conclusion of this paper, we propose a heuristic model to aid in that effort.

\section{3: Perceptions of procedures and decisions should not be studied devoid of context. In field research, context should be well described. In lab research, context should be controlled for or manipulated. We note several context variables that research indicates must be considered.}

3a: The type of job for which applicants are applying, and job and organization attractiveness, appear to be influences on perceptions. The type of job has been shown to influence how a particular procedure is viewed (e.g., Kravitz et al., 1994), although this is under-researched. One would expect that judgments of job-relatedness would be influenced by the job. For example, research has shown that the acceptability of drug testing as a selection tool is influenced by job characteristics (Murphy, Thornton, \& Prue, 1991; Murphy, Thornton, \& Reynolds, 1990). In developing models of antecedents of perceptions, we need to specify what specific job characteristics are expected to influence perceptions. For example, does the degree of social interaction required in a job affect perceptions regarding the use of personality tests? Does the technology level of the job influence perceptions of computerized testing?

Although there has been little research on attractiveness as an antecedent or correlate of reactions, it seems that one might see a more attractive organization as having better selection processes. For example, McCulloch and Turban (1997) found that those who had concerns about a life insurance sales job viewed integrity tests more negatively than those without such concerns. It may be that cognitive dissonance leads one to alter procedure perceptions to be in line with job desirability perceptions (i.e., this is a high paying job so their procedures are "thorough" rather than "invasive"). Similarly, an acceptable reason for not pursuing a job would be "their process turned me off," rather than acknowledging a lack of qualifications. Alternatively, individuals may actually view the content of selection procedures for jobs they desire more positively. Attractive organizations may be ones that have the most attractive methods of hiring.

$3 b$ : Information provided to applicants regarding a procedure (e.g., constructs assessed, reasons for use) and/or decision (e.g., explanations for rejec- 
tion) can make a difference in perceptions; such information should be detailed in study descriptions. Ployhart et al. (1999) found that providing information on why an individual was accepted or rejected (e.g., due to what particular procedure in the process) influenced perceptions of process fairness. This is consistent with the literature on social accounts (Bies, 1987; Bies \& Shapiro, 1988; Greenberg, 1990, 1994). However, Gilliland (1994) did not find providing an explanation to relate to fairness perceptions. In field studies, we typically are not provided with much information on how applicants were informed of the decision. Research is needed on what applicants are told and how this is perceived.

In addition to how decisions are explained, researchers should attend to what information is provided about the procedure itself. For example, are applicants told what construct is to be assessed? Have applicants been given a reason why a test is used? Horvath, Ryan, and Stierwalt (in press) found that explanations for why a procedure was used affected fairness perceptions. Crant and Bateman (1990) found that giving an explanation for why drug testing was used affected attitudes toward a company and intentions to apply. Without knowing what applicants are told about a procedure, it is difficult to assess what is driving perceptions. For example, simply being told that a measure is job related may enhance job-relatedness perceptions.

3c: Procedures may be viewed differently depending upon what else is part of the process. Rosse, Miller, and Stecher (1994) demonstrated that perceptions of a personality test were influenced by what other selection procedures were used in the hiring process. Ryan et al. (1996) found opinions on the order of test administration to relate to fairness perceptions. They also suggested that applicants might prefer compensatory selection processes, where they participate in all selection procedures, to multiple hurdle processes, where individuals are excluded at each step. Unless organizations are using a procedure in isolation, studying it in isolation does not make sense. If a procedure is hardly ever used as an initial screening hurdle, treating it as such in a research study is inappropriate. It is important that we consider how inclusion/exclusion of procedures, order of procedures, and the compensatory/noncompensatory nature of the process might influence applicant perceptions.

3d: Organizational context may influence perceptions. Arvey and Sackett (1993) noted that context will influence applicant reactions, yet this has not been systematically examined in the literature. For example, they suggest that organizational history, selection ratio, and organizational resources may influence fairness perceptions. However, Thorsteinson and Ryan (1997) did not find selection ratio to relate to fairness perceptions. Researchers using civil service samples (e.g., Ryan et al., 1998; Ryan et al., 2000; Schmit \& Ryan, 1997; Truxillo \& Bauer, 1999) note that the public nature of testing, presence of strong affirmative action efforts, and histories of discrimination appear to influence perceptions of selection processes. Given that studies of applicant perceptions have not been multiorganizational, it may take an accumulation of research in different contexts before any conclusions regarding organizational context influence can be made. 
However, ignoring the role of these variables in discussions of perceptions is misleading.

3e: Reactions to promotion processes and decisions may be very different from those for organizational entry positions. Research has indicated that identification with the organization may play a key role in how one interprets the fairness of a process (Brockner, Tyler, \& Cooper-Schneider, 1992; Huo, Smith, Tyler, \& Lind, 1996; Tyler \& Degoey, 1995). Reactions to promotional procedures deal with individuals who are members of the organization. Thus, we might expect different mechanisms underlying attitude formation. Truxillo and Bauer (1999) found racial differences in perceptions of banding in a promotion sample, but not among entry-level applicants. They suggest that individuals within the organization may be in possession of different information regarding procedures and procedure use.

A few studies have examined perceptions of incumbents in comparison to those of applicants and have found differences, with applicants typically exhibiting more positive perceptions (e.g., Arvey et al., 1990; Brutus \& Ryan, 1998). One concern this highlights is that regardless of anonymity assurances, applicant reports of perceptions may be influenced by socially desirable responding. Alternatively, because applicants often possess little information about the job (Barber, 1998), their judgments of job-relatedness and fairness may differ from those of incumbents who have intimate knowledge of the job. Interestingly, Smither et al. (1993) found more experienced managers to have more positive perceptions than new hires of the job-relatedness of only 2 of 14 selection procedures. Finally, applicants may, indeed, simply feel more positively. For example, studies assessing the test-taking motivation of applicants (Schmit \& Ryan, 1997; Ryan et al., 1998, 2000) typically find a high mean and restricted range. This raises concerns about how studies of test-taking motivation with nonapplicant samples (e.g., Chan et al., 1997) might generalize to highly motivated applicant samples.

\section{4: Individual differences as potential antecedents of perceptions remain largely unexplored.}

Arvey et al. (1990) noted the need to assess whether test taker attitudes are more determined by individual differences or situational characteristics. They note that if the former is true, organizational interventions to affect attitudes may not have large effects. Yet, few studies have looked at individual difference correlates. Indeed, few studies have looked at subjects across multiple types of procedures. Fewer still have looked at subjects longitudinally, either across one selection process or across different job search cycles. We need such research to determine how malleable applicant perceptions are.

Applicants are likely to be drawing on their own past experiences and personal characteristics in making evaluations. Research has shown previous experience with a procedure to influence perceptions (Kravitz et al., 1994; Ryan et al., 1996). Brutus and Ryan (1998) found perceptions of the job-relatedness of various selection procedures to be related to individual differences in preferences and personality that would lead to good performance on those instruments. For example, those who preferred to work alone or had conflictual relations with 
positive perceptions of distributive justice, potentially because they have been socialized to be more accommodative (Boldizar, Perry, \& Perry, 1988; Major \& Deaux, 1982). Yet, potential gender differences in distributive justice perceptions in selection contexts remain unexplored.

\section{6: Social information has been neglected as an influence on perceptions.}

Research suggests that individuals rely on cues from others when making fairness assessments (Ambrose, Harland, \& Kulik, 1991; Lind \& Tyler, 1988). However, the applicant perceptions literature has not really examined how the opinions of others influence perceptions of an organization's selection process (one exception is Bazerman, Schroth, Shah, Diekmann, \& Tenbrunsel, 1994). Such comparisons have been the basis of much equity theory research on outcome fairness. It may be that applicants change perceptions once they have a chance to gather some comparison information from friends and family about whether the procedure they experienced was fair or unfair in the eyes of others.

\section{What are the Consequences of Perceptions (i.e., To What Outcomes Have They Been Linked)? What Moderates These Relations?}

Column 7 of Table 1 indicates the major dependent variables in applicant perceptions research. Perceptions have been linked to test performance in that studies have shown that test-taking attitudes both influence and are influenced by test performance. Thus, in a given situation an applicant's motivation is likely linked to previous outcomes on similar devices and also influences how he or she performs in the current situation (Chan et al., 1997). Perceptions of procedures may influence organizational attractiveness (e.g., Bauer et al., 1998). Research has also shown correlations between perceptions of procedures (e.g., job-relatedness, fairness) and intentions to accept a job and recommend an organization.

Researchers have demonstrated that perceptions of a procedure influence self-perceptions after a selection or rejection decision. Ployhart and Ryan (1997) indicated that there are process $\times$ outcome interactions, such that a combination of fair procedures and positive outcomes can have positive effects on selfperceptions. However, being hired under unfair procedures can actually have negative effects on self-perceptions. A different effect occurs for rejected applicants. There is some evidence that being rejected by a fair procedure leads to lowered self-perceptions.

In terms of links between perceptions and applicant behavior, Ryan et al. (2000) showed no connection between perceptions of the process and applicant decisions to drop out of the process. No studies have examined the links between perceptions and actual offer acceptance. Gilliland (1994) showed that job-relatedness perceptions influenced subsequent job performance.

Some key themes emerge after examining this research question:

\section{7: Aside from test performance, few studies assess actual behavior.} Researchers have not demonstrated that applicant perceptions "matter."

Because most studies do not assess actual behaviors of applicants (such as do they accept offers, do they self-select out), we may be overestimating the influ- 
others did not see an interpersonal skills test as job-related. Researchers have suggested that those with high negative affectivity might have lower perceptions of process and outcome fairness (Ball et al., 1993). However, Greguras and Ryan (1997) did not find perceptions of tests to be related to negative affectivity. We would also suggest openness to experience might affect perceptions of more novel procedures and processes. Three decades ago (Fiske, 1967), it was noted that personality might be a source of variance in reactions to tests: it is time to better explore that possibility in organizational contexts. At the very least, the role of one's evaluative history (i.e., how well one has done on similar procedures in the past ) should be assessed.

\section{5: Racial differences in perceptions are sometimes found; appropriate descriptions of context are needed to develop a greater understanding of when they will occur.}

The work of Chan and colleagues (Chan et al., 1997, 1998a, 1998b) clearly indicates that racial differences in perceptions of cognitive ability tests may explain and/or be explained by race differences in test performance. However, race differences have not been found in perceptions of personality tests (Chan, 1997) and have been found to be less for certain methods of testing (Chan \& Schmitt, 1997). Thus, test type and test format appear to interact with race in the formation of perceptions. Ryan and Greguras (1998) noted that although there is an implicit assumption that minority applicants view performance assessments more favorably than multiple-choice testing, there has not been much research on this point that avoids a confound of test content and format. Because the research on test characteristics that influence perceptions is limited as we noted above, we feel that interactions of test characteristics and race would be a fruitful area of investigation.

Further, whether racial differences in perceptions are present in real-world settings is likely highly influenced by context. In several studies (Ryan, Ployhart, Greguras, \& Schmit, 1997; Schmit \& Ryan, 1997), African-Americans had more favorable views than whites of the fairness of an ability test in contexts where there were strong affirmative action programs and minorities in visible leadership positions within the organization. In a law enforcement organization with poor relations with the minority community, Ryan et al. (2000) found that AfricanAmericans had more negative perceptions of all aspects of the process (written test, oral boards), although effects were quite small. Similarly, Lemons and Danehower (1997), in a study of perceptions of promotion decisions, found that perceptions of distributive justice increased as the number of female role models in the organization increased, and decreased as departmental segregation increased.

We noted in our opening paragraph that concerns about racial differences in perceptions and the potential effects of these on minority recruiting are a driving force behind applicant perceptions research. At the same time, we find a need for considerably more research if we are to understand when and why these differences might occur. We also note that gender differences have not been systematically examined. There is some research that indicates women tend to have more 
ence of applicant perceptions. Granted, many studies do assess intentions, but potential moderators of intention-behavior links are not considered. Also, Macan et al. (1994) pointed out that job and organizational attractiveness had stronger influences on behavior than applicant perceptions of the selection process. Studies that do not measure and consider these correlates of perceptions might inappropriately infer that perceptions of procedures have a larger influence on behavior than they do.

One problem with the behavioral variable most assessed, test performance, is that studies assume a causal order that is seldom demonstrated. That is, do perceptions influence performance or does previous test performance (which would be correlated with current test performance) influence perceptions? Chan et al. (1997) demonstrated that test-taking motivation did affect performance after controlling for prior performance. However, this issue remains unexamined with other types of applicant perceptions (e.g., fairness) and procedures other than cognitive ability tests.

Applicant self-selection out of a hiring process has not been found to be linked to perceptions of the process (Ryan et al., 2000; Ryan \& McFarland, 1997a; Ryan et al., 1997; Schmit \& Ryan, 1997), despite the suggestion of a relation by many researchers. Schmit and Ryan (1997) suggested that process unfairness may lead to withdrawal behavior for only a small percentage of applicants (i.e., less than $10 \%$ ); studies examining retrospective reasons for withdrawal gathered via interviews have supported that contention (Ryan \& McFarland, 1997a; Ryan et al., 1997; Ryan et al., 2000). Rather than assuming strong perception-behavior relations, we should pursue why some individuals act on negative perceptions but many do not. Also, we need to examine whether these individuals are ones the organization considers desirable applicants.

Given the lack of attention to actual behavior, one may question the value of any of the research we have reviewed. We feel this research does contribute to our understanding of what influences perceptions, how perceptions change over the course of the selection process, and whether justice theory propositions are applicable to the selection context. However, unless greater attention is given to behavioral outcomes, we feel the research will be dismissed as practically irrelevant.

\section{8: Only about 10\% of studies include pre-test measures. Some "outcome"} variables may also serve as antecedents (e.g., general attitudes toward test fairness, test-taking self-efficacy (Bauer et al., 1998)).

Without assessing attitudinal measures (e.g., organizational attractiveness) and intentions prior to participating in the selection process, one is hard pressed to be able to definitively attribute a causal order. That is, applicant perceptions of the selection procedure may cause intentions and attitudes, or these intentions and attitudes may lead one to hold certain perceptions of the procedure. For example, as we noted earlier, one may view an organization as attractive and this can cause one to see the selection process in a more favorable light. Powell (1991) noted that research on self-fulfilling prophecies in applicants' decisions about jobs is necessary. Rynes (1991) stated that applicant perceptions and behavior are likely to 
be influenced by different determinants at different points in the process; thus, time of measurement is an important concern. Researchers need to move away from post-test designs to designs that incorporate pre- and post-measures when possible.

\section{9: Self-perceptions appear to be influenced by perceptions of selection} procedures (Gilliland, 1994; Ployhart \& Ryan, 1997; Ployhart et al., 1999), but may also influence them.

The literature on preferential selection provides some insights regarding effects of selection processes on self-perceptions. Being hired preferentially leads to lowered self-perceptions of competence and lowered task performance (Heilman et al., 1987, 1990; Heilman, Rivero, \& Brett, 1991), but such effects seem to occur for women and not for men. The implication is that benefiting from an "unfair procedure" is viewed differently by different groups. Heilman proposes that this is due to initial self-perceptions being more negative for women. The implication for applicant perceptions research in general is that an applicant's initial self-view may affect perceptions and perception-outcome links. Thus, it is important to understand the role of self-perceptions as an antecedent and not just a consequence of applicant perceptions of procedures.

\section{0: There is some suggestion that perceptions may moderate the validity of selection procedures.}

Arvey et al. (1990) suggested that test-taking attitudes might affect the validity of a test and there has been some support for this in lab (e.g., Schmit \& Ryan, 1992; Thorsteinson \& Ryan, 1997) and field studies (Barbera, Ryan, Desmarais \& Dyer, 1995; Ryan \& McFarland, 1997b). Individuals who perceive a selection tool as low in predictive validity or unfair may know that they "test poorly" and that the test is not predictive for them. These studies have generally found small effects; however, small changes in validity can be practically meaningful.

\section{1: Research on potential moderators of perception-outcome links has been limited.}

Applicant perceptions research typically considers the direct effects of perceptions on various attitudes, intentions, self-perceptions, and behaviors. Given the complexity of real-world selection settings, it is likely that moderators exist. Further, theories such as justice theory and behavior intention models predict a number of such interactions. For example, Ployhart and Maynard (1999) found that complex interactions exist between job-relatedness, the hiring decision, job desirability, and selection ratio for predicting organizational attitudes and job choice. This suggests that the applicant perception-behavior link might be conditional on job desirability or the amount of competition for the job. For example, fairness-behavior relations might be stronger when the job is highly desirable (perhaps because of good pay, a desirable location, or excellent benefits), the applicant already has an acceptable job or lacks desirable alternatives, or the economy is strong. Indeed, Gilliland (1993) proposed the expectation of being hired to be a key moderator in his justice model. 
Bazerman et al. (1994) suggested that the availability of alternative offers would affect the role procedural justice information plays in making a decision about offer acceptance. In a study of interviewer characteristics, Liden and Parsons (1986) found alternative opportunities moderated the relation between affective reactions and job acceptance intentions. Bazerman et al. (1994) noted that when people are questioned about their feelings concerning a single procedure they report being far more concerned about fairness than when asked about their choice among several procedures. Much of the research on applicant perceptions focuses on a single situation (i.e., the fairness of this process for this position). We need to examine the role of perceptions in determining behavior of applicants who have multiple options available.

Another potential moderator of the perception-outcome link is social support. Justice research on revenge indicates that social support plays a key role in allowing individuals to vent about an injustice and may lead to ruminating on the injustice to the point of taking action (Bies \& Tripp, 1998; Bies, Tripp, \& Kramer, 1997). Whether applicants act on negative perceptions may be dependent upon the opinions and urgings of others.

In sum, there has not been a lot of exploration of potential perceptionbehavior moderators. Exploration of moderators needs to occur within true experimental designs. To adequately develop a framework of potential moderators, we suggest researchers do not "reinvent the wheel" by ignoring the large literature on recruitment and choice, which provides guidance on what influences applicant behavior.

\section{What Theoretical Frameworks Have Been Presented? How Well Have They Been Applied? What Other Theoretical Viewpoints Need Consideration?}

The predominant theoretical framework that has been applied to studying applicant perceptions is a social justice framework. Although Gilliland's model (Gilliland, 1993) is well received by researchers, little empirical work has focused on specifically testing the propositions of the model (for exceptions see Bauer et al., 1998; Gilliland, 1994; Ployhart \& Ryan, 1998; Ryan \& Chan, 1999b). Many researchers do not measure or manipulate the procedural or distributive justice rules or their antecedents. For example, Gilliland (1993) presented specific propositions about which procedural justice rules should be influenced by test type, which will be influenced by human resource policy, and which will be influenced by the behavior of HR personnel. He also proposed that justice rule perceptions will explain most of the variance in perceptions of process fairness and provided several propositions regarding rule weighting and rule salience. Yet, these propositions remain largely untested. For example, Ryan and Chan (1999b) found only one rule-job-relatedness - had effects on fairness perceptions of a licensure examination, and it was the only one for which respondents had negative perceptions. Thus, in terms of "what leads to fairness perceptions," theory has largely been unapplied in applicant perceptions research. 
The other side of Gilliland's model is the connection of fairness perceptions to individual and organizational outcomes. Here, we note a greater research focus (e.g., Ployhart \& Ryan, 1997), but shortcomings as well (i.e., studies have not assessed actual behaviors subsequent to participating in the process itself). For example, Gilliland (1993) proposed that perceptions of underpayment inequity that result from not receiving a job when it is expected will result first in anger and, then, in organizational and self devaluing. No one has examined a sequential set of applicant reactions to a hiring decision. In sum, although justice theory is often invoked in this research arena, many of the propositions derived from justice theory remain untested.

Attribution theory has received some attention in the applicant perceptions literature (Arvey et al., 1990; Kluger \& Rothstein, 1993; Ployhart \& Ryan, 1997). In social psychology, causal attributions are considered to be a critical component of social perception (e.g., Fiske \& Taylor, 1991; Weiner, 1986) and form the basis for a variety of expectations, intentions, and behaviors (Weiner, 1985, 1986). Thus, to what an applicant ascribes the cause of a selection or rejection decision is likely to be a very strong influence on his or her future behavior. Ployhart and Ryan (1997) found that individuals who were selected reported the selection decision to be caused by more internal, stable, and controllable factors (and those who were rejected reported external, unstable, and uncontrollable causes). This is consistent with social psychology's definition of the self-serving bias (e.g., Fiske \& Taylor, 1991). Interestingly, the self-serving bias was only found when the procedures were also perceived as fair. The finding of applicants exhibiting a self-serving bias in selection contexts has been found in other studies, although it has typically been operationalized and measured in ways different from those described in the attribution theory literature (e.g., Chan et al., 1999; Ployhart \& Ryan, 1998; Ryan \& Chan, 1999b). What are perceived as fair are procedures and outcomes that are favorable for the applicant.

Research seems to support the existence of an applicant self-serving bias, but this is just one of a number of biases suggested by attribution theory. For example, the false-consensus effect occurs when individuals judge their own behavior as being typical, and that others would perform the same behaviors in the same circumstances (when in fact they would not) (Fiske \& Taylor, 1991). In applicant perceptions research, one might see the false-consensus effect when applicants who refuse to buy products from a company that did not hire them believe this is a common behavior. In addition to various attribution biases, there are also a variety of alternative attribution theories that have not been explored in applicant reactions research. Fiske and Taylor (1991) provide a nice summary of these various approaches.

We suggest the following theoretical considerations in future research:

\section{Better Testing of Gilliland's Model, and Social Justice Theory Propositions in General}

We noted above the limited testing of Gilliland's model in that few studies have systematically manipulated justice rules. We also need to be concerned with how justice theory applies to a selection setting. A selection context differs from 
other arenas of organizational justice that researchers have investigated because of the lack of a relation between the applicant and organization. Tyler and Dawes (1993) stated that in situations without strong social bonds, people will be egoistical. We noted above the self-serving bias finding in the applicant perceptions literature. Further, researchers have not found the types of process by outcome interactions found in other justice research. Brockner and Wiesenfeld (1996) indicated that procedures matter most when outcomes are unfair or undesirable, yet Ployhart and Ryan (1997) indicated that procedures matter most when outcomes are seen as fair. Ployhart and Ryan noted that this is partly a function of the types of intentions one examines and also perhaps a function of the fact that applicants often have alternative offers they can pursue when rejected. Rather than expecting findings similar to those in other organizational justice areas (e.g., performance appraisal, layoffs), basic social justice theory would predict potentially different findings in a selection context because of the nature of the applicant/organization relationship (i.e., one-shot, limited scope). Of course, those who are accepted by an organization and accept the offer do then commence an ongoing relationship. Justice theory might make different predictions about this group than about other applicant groups.

Also, some aspects of basic theory have been neglected in the applicant perceptions area. For example, Adams' equity theory formulation (Adams, 1965) predicts that the reaction to inequity will be proportional to the magnitude of the inequity, and research has supported this (e.g., Greenberg, 1988). In a selection setting, we need to think about what the likely reaction of an applicant would be if he or she were given an inequitable outcome (i.e., what is the magnitude of the inequity for the applicant). For example, perhaps the reaction is stronger if it is a highly desirable job (e.g., high-paying or high-status) than if one feels an unfair rejection occurred for a low level, generic job.

\section{Consider Other Theoretical Formulations and Models}

Our understanding of the nature and consequences of applicant perceptions would be enhanced by looking outside the justice literature. As we noted in the section on types of perceptions that have been studied, fairness is but one type of perception an applicant might hold. Frameworks other than justice theory may prove valuable in exploring a wider range of applicant perceptions. However, we note that other existing frameworks (e.g., Arvey \& Sackett, 1993) do not provide much understanding of the processes' underlying perception formation or perception-outcome links.

Basic research on attitude formation, measurement, and effects is particularly relevant to applicant perceptions research. As noted earlier, the second predominant stream of research focuses on test-taking attitudes and motivation (e.g., Arvey et al., 1990; work of Chan and colleagues). Research on test-taking attitudes has not been well-grounded theoretically (e.g., test-taking motivation is not well tied to leading theories of motivation such as expectancy theory; self-efficacy is not considered in light of research on how self-efficacy perceptions are formed (Gist \& Mitchell, 1992)). Indeed, although this research is on testtaking attitudes, little connection is made to basic attitude research and theory. 
One interesting concept is attitude strength. Krosnick and Petty (1995) reviewed the attitude strength literature and suggested it has two components: durability (or stability) and impactfulness (how much the attitude influences other processes). Thus, more durable and impactful attitudes have a stronger influence on behaviors than attitudes lacking these qualities. One can borrow the durability and impactfulness conceptualizations to examine fairness perceptions, test-taking attitudes, and a variety of other applicant perceptions. For example, if test-taking motivation is easily changed (i.e., lacks durability), it may not be strongly held and may not have a consistent relation with applicant behavior.

Another example of attitude research that may be relevant is that on behavioral intention models (e.g., Ajzen \& Fishbein, 1980; Ajzen \& Madden, 1986; Fishbein \& Ajzen, 1975). This research suggests intentions are determined by beliefs, attitudes, subjective norms, and perceptions of control (e.g., Ajzen \& Fishbein, 1980). Such intention models might also serve to supplement justice models or be more formally integrated with them to better understand how applicant perceptions connect to applicant behavior. As we noted earlier, social information (such as subjective norms) is not examined well in this research. Perceptions of control are also unexplored, yet they have been suggested as key influences on applicant views of the selection process (Schuler, 1993).

Research on cognitive consistency theories (e.g., cognitive dissonance, balance theory) might also be used to understand reactions to selection decisions (see Abelson et al., 1968; Heider, 1958, for classic examples; and Fiske \& Taylor, 1991, for a more recent treatment). Cognitive dissonance suggests that, when there are inconsistencies between a person's behavior and attitudes, the discrepancy will create dissonance and thus motivate the person to reduce the discrepancy. The most typical form of discrepancy reduction is to change one's attitudes to be aligned with the behavior (Fiske \& Taylor, 1991). For example, if an applicant applies for a desirable job but then learns the organization uses a selection process he or she is unlikely to do well on, the individual may withdraw from the process and change his or her perceptions of the organization to less favorable ones. One very important feature of cognitive consistency theories is the notion of selective perception. Selective perception suggests that individuals will only attend to information that supports their existing attitudes. For example, if an applicant already holds negative attitudes toward a selection process (e.g., feels cognitive ability tests are unfair), he or she may be highly sensitive to minor justice rule violations (e.g., see a by-the-book test administrator as poor interpersonal treatment).

\section{New Directions}

Figure 1 provides a heuristic model of what we see as the key antecedents, outcomes, and perceptions to be studied, as well as a number of suggested moderators. We borrow from Gilliland's justice model (Gilliland, 1993) and Brutus and Ryan's model of determinants of perceived job-relatedness (Brutus \& Ryan, 1998). One contribution of this heuristic is the categorizing of types of applicant perceptions into perceptions of the procedure/process (e.g., justice rule 


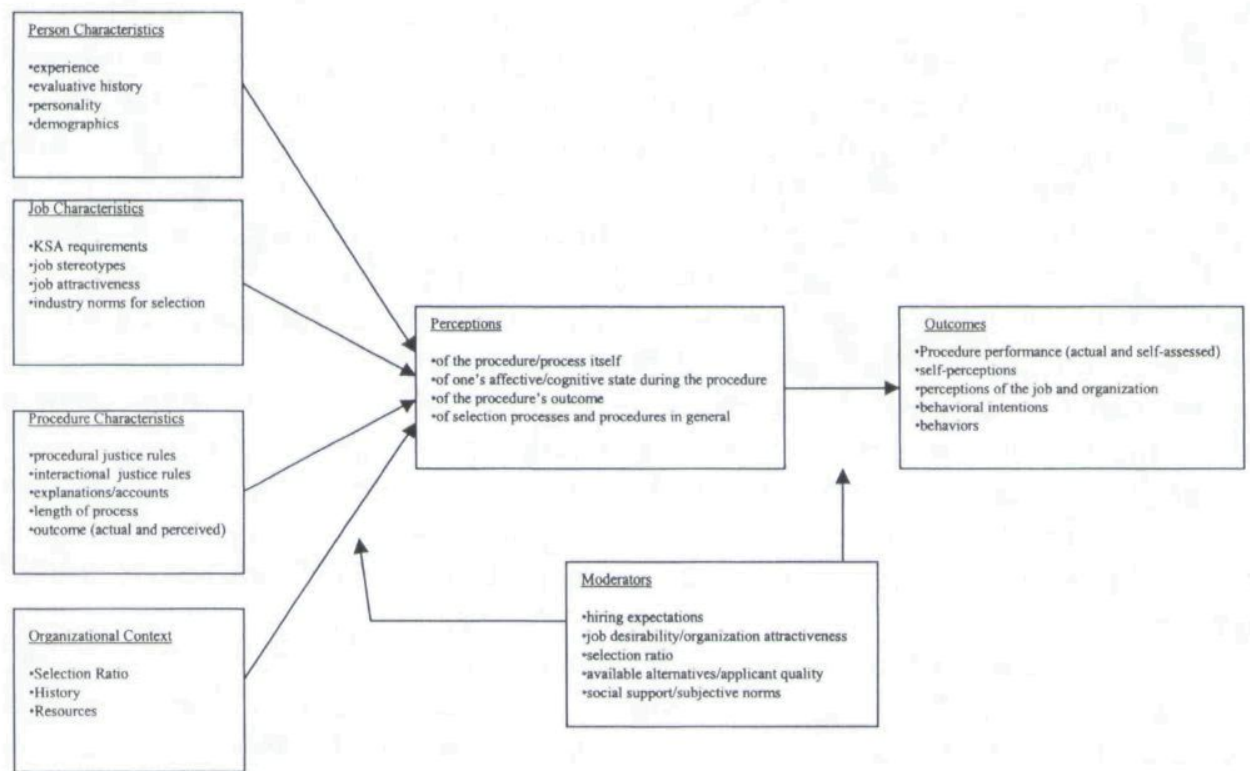

Figure 1. Heuristic Model

violations, fairness, ease), of one's affective and cognitive state during the procedure (e.g., motivation, anxiety), of the procedure's outcome (e.g., distributive fairness), and of selection processes and procedures in general (e.g., belief in tests, views on affirmative action, preferences for evaluation methods). We feel that more systematic research on the various determinants and outcomes in this model would move this area of research forward greatly.

In addition to the specific research ideas mentioned throughout the paper, there are several other issues applicant perceptions researchers need to address. First, we need to consider the stability of various perceptions across the course of a selection process. Researchers have noted changes in perceptions from pre- to post-test (e.g., Chan et al., 1998b) and from post-test to post-outcome (e.g., Ployhart \& Ryan, 1998). More distal assessments (e.g., months post-outcome) may differ as well, as individuals "get on with their lives" or experience alternative procedures with other employers as part of their job search. We reiterate the importance of considering time of measurement in evaluating study generalizability, given what we know to be the natural sequence of events in employee selection.

Second, perhaps there are nonlinear relations between perceptions and behaviors. For example, applicants might not pursue legal action until there is some "breaking point" in terms of what they see as discriminatory behavior. Gilliland, Benson, and Schepers (1998) showed that when one has to make a decision about taking action based on considerations of fairness, if more than three justice rule violations have occurred, any non-violations are not considered. When making judgments of fairness, justice violations and nonviolations are equally important. 
In a selection context for a decision about accepting a job offer, it may be that greater weight is given to what is wrong in the process (e.g., the receptionist was rude when she gave me the test) than to what is right. Further, Gilliland (1995) noted that some procedural justice rules are more salient in their violation while others are more salient in their satisfaction, suggesting potentially complex relations with behaviors. Future research directed at understanding how violations and nonviolations combine to influence decisions is needed.

Third, a multiple stakeholder perspective might be helpful. There are others besides applicants who are stakeholders in the selection process, and their perceptions may influence key organizational outcomes. For example, we know little about incumbent managers' perceptions of hiring processes (e.g., Smither et al., 1993). These perceptions might influence important outcomes, such as willingness to use a selection procedure (or to use it as intended) or views and acceptance of new hires. Another group of stakeholders are those in HR with responsibility for administering and evaluating procedures. For example, if a test administrator views a procedure negatively, he or she may adhere less strictly to protocol and be more willing to "assist" applicants on a procedure. Recruiters with negative perceptions of structured interview questions might skip what they see as irrelevant.

Fourth, prominent applicant perceptions researchers such as Chan and Ployhart have repeatedly called for more experimental research (Chan et al., 1998b; Ployhart \& Ryan, 1998), even if such research is lab based with student populations. This may seem counter to a need to study actual applicants and actual behaviors. For example, college students are more experienced and comfortable with being tested than those with lower levels of education or who are long removed from the educational system (Ryan \& Greguras, 1998). However, these researchers point out some major concerns. First, we cannot assess the effects of a particular justice rule (such as job-relatedness), what leads to a rule being seen as violated, how individual and situational characteristics affect rule salience, etc., unless we conduct research where that rule is systematically manipulated. Such manipulations are less likely to be possible in field settings, where treating one group of applicants differently from another can be seen as unethical or even illegal. Second, we cannot develop a good theoretical understanding of how and why perceptions have effects on personal and organizational outcomes unless we conduct experimental research that enables us to isolate mediators and moderators. Measuring or manipulating these is also less likely in a field setting.

Fifth, Rynes (1993) noted that to identify applicant likes and dislikes, intensive qualitative research should precede surveying. This has not been the case in the applicant perceptions research arena (exceptions include Gilliland, 1995; Ployhart, McFarland, \& Ryan, 1998). Rynes noted that doing as she suggested would "avoid the opposing dangers of either prematurely settling on one potentially deficient model, such as justice or expectancy theory, or contribution to underlying process obfuscation via proliferation of seemingly different, but actually similar, constructs" (Rynes, 1993: 252). We feel it is not too late for researchers in this area to heed her warning and backtrack to do intensive 
qualitative research (e.g., verbal protocol analysis) of applicant perceptions of procedures to formulate a more meaningful framework for this research.

\section{Conclusions}

What should an organization do about its selection process based on this literature? We would not advocate that organizations remove valid procedures because of suspected negative reactions. At this stage, we do not have enough evidence that negative perceptions of applicants actually have negative effects (i.e., relate to turning down jobs, badmouthing the organization). Also, given the many potential determinants and moderators of perceptions, generalizations from reported research on a "similar" method may not be prudent. However, the literature on applicant perceptions, as well as the more basic literature on social justice, provides some clear "good ideas" that seem unlikely to harm and likely to help both organizations and individuals.

1. Recognize that Test-Taking Attitudes Influence Performance in the Selection Process. Chan and colleagues have demonstrated that test-taking motivation can influence performance. Employers may protest that it is not their role to motivate applicants and that they do not want to hire "unmotivated" employees. However, test-taking motivation is not necessarily an indicator of motivation to do a job-it may be influenced by an individual's experiences with a particular type of test. Employers can look at whether their particular selection process demotivates applicants (e.g., is it too lengthy) or unduly raises anxiety (e.g., nature of instructions).

\section{Provide Explanations that Give Information and are Delivered in an} Interpersonally Sensitive Manner (Greenberg, 1990, 1994). However, as noted by several researchers (e.g., Bies, 1987; Ployhart et al., 1999), using social accounts to "manage" a situation can lead to distortion of the truth or inappropriate rationalizations. For example, an organization could argue that a procedure with high adverse impact was necessary to maintain a competitive advantage. While this might be true, giving such an explanation does not address the issue of what an organization might do to reduce adverse impact. We note that the research on social accounts has typically focused on cases where there are ongoing relationships between the explanation provider and recipient (Bies, 1987; Bies \& Sitkin, 1992). It is unclear how this then applies to a selection context, where the interaction between the applicant and the organization may be a single-time encounter, with no ongoing relationship. We also lack descriptive research on what types of explanations or accounts are currently used in selection contexts or what strategies organizations use in informing applicants of rejection. Our suspicion is that most organizations use a "there were many more qualified applicants than openings" boilerplate statement when explaining a rejection decision.

3. Regularly Monitor Applicant Perceptions. When approached about research, a number of organizational contacts have told us they do not want to ask about things like the fairness of their selection process for fear that it "will plant seeds in applicants' minds." The idea of a priming effect is not without scientific merit (Feldman \& Lynch, 1988). However, asking incumbents or students for 
their perceptions does not appear to be a sufficient surrogate for asking actual applicants. Regular monitoring of perceptions can alert an organization to shifts in the quality of selection process administration as well (e.g., pinpointing uninformative interviewers, noting delays in the process).

4. Assess Perception-Behavior Links. Laboratory research can only go so far in assessing the types of behavior of interest (e.g., job offer acceptance). Such links need to be examined in order for researchers to confidently assert that "applicant perceptions matter." In particular, we note that there is not as yet solid evidence that desirable applicants turn down job offers because of their views of the selection process.

5. Recognize that Selection Involves Evaluation. As Fiske (1967) noted, reactions to tests are not just reactions to the procedure itself, but are reactions to being evaluated. Regardless of what changes are made to tools used in decisionmaking, selection is an evaluative process. The real issue is not the total elimination of negative perceptions, but an understanding of whether those who hold negative perceptions are desirable applicants and, if so, how to make certain those perceptions do not affect important behaviors (e.g., accepting job offers). There is much organizations can do to improve applicant perceptions, but such undertakings must not supplant the use of reliable and valid predictors, nor can they erase the fact that, in selection, some people will be unhappy with the negative outcomes they receive.

Applicant perceptions of selection procedures have generated considerable research and applied interest. However, we come to a pessimistic conclusion regarding whether perceptions really matter, as there has been insufficient empirical demonstration of links to behaviors or distal attitudes and self-perceptions. We do feel that this remains an open question and hope that clearer demonstrations of value occur soon. As the area of research matures, a more theoretical and integrated approach is needed. We hope this review can serve as a starting point for that integration.

\section{References}

Abelson, R. P., Aronson, E., McGuire, W. J., Newcomb, T. M., Rosenberg, M. J., \& Tannebaum, P. H. 1968. Theories of cognitive consistency: A sourcebook. Chicago: Rand McNally.

Adams, J. S. 1965. Inequity in social exchange. In L. Berkowitz (Ed .), Advances in experimental social psychology, Vol. 2: 267-299. New York: Academic Press.

Ajzen, I., \& Fishbein, M. 1980. Understanding attitudes and predicting social behavior. Englewood Cliffs, NJ: Prentice-Hall.

Ajzen, I., \& Madden, T. J. 1986. Prediction of goal-directed behavior: Attitudes, intentions, and perceived behavioral control. Journal of Experimental Social Psychology, 22: 453-474.

Ambrose, M. L., Harland, L. K., \& Kulik, C. T. 1991. Influence of social comparisons on perceptions of organizational fairness. Journal of Applied Psychology, 76: 239-246.

Arvey, R. D., \& Sackett, P. R. 1993. Fairness in selection: Current developments and perspectives. In. N. Schmitt \& W. C. Borman (Eds.), Personnel selection in organizations: 171-202. San Francisco: Jossey-Bass.

Arvey, R. D., Strickland, W., Drauden, G., \& Martin, C. 1990. Motivational components of test-taking. Personnel Psychology, 43: 695-716.

Ball, G. A., Trevino, L. K., \& Sims, H. P. 1993. Justice and organizational punishment: Attitudinal outcomes of disciplinary events. Social Justice Research, 6: 39-66.

Barber, A. E. 1998. Recruiting employees: Individual and organization perspectives. Thousand Oaks, CA: Sage. 
Barbera, K. M., Ryan, A. M., Desmarais, L. B., \& Dyer, P. J. 1995. Multimedia employment tests: Effects of attitudes and experiences on validity. Presented at the Tenth Annual Conference of the Society for Industrial and Organizational Psychology, Orlando, FL.

Bauer, T. N., Maertz, C. P., Dolen, M. R., \& Campion, M. A. 1998. Longitudinal assessment of applicant reactions to employment testing and test outcome feedback. Journal of Applied Psychology, 83: 892-903.

Bazerman, M. H., Schroth, H. A., Shah, P. P., Diekmann, K. A., \& Tenbrunsel, A. E. 1994. The inconsistent role of comparison others and procedural justice in reactions to hypothetical job descriptions: Implications for job acceptance decisions. Organizational Behavior and Human Decision Processes, 60: 326-352.

Bies, R. J. 1987. The predicament of injustice: The management of moral outrage. In L. L. Cummings \& B. M. Staw (Eds.), Research in organizational behavior. Greenwich: JAI Press.

Bies, R. J., \& Shapiro, D. L. 1988. Voice and justification: Their influence on procedural fairness judgments. Academy of Management Journal, 31: 676-685.

Bies, R. J., \& Sitkin, S. B. 1992. Explanation as legitimization: Excuse-making in organizations. In. M. L. McLaughlin, M. J. Cody, \& S. J. Read (Eds.), Explaining one's self to others: Reason-giving in a social context: 183-198. Hillsdale, NJ: Erlbaum.

Bies, R. J., \& Tripp, T. M. 1998. Revenge in organizations: The good, the bad, and the ugly. In R. W. Griffin, A. O'Leary-Kelly, \& J. M. Collins (Eds.), Dysfunctional behavior in organizations: Non-violent dysfunctional behavior: 49-67. Stamford, CT: JAI Press.

Bies, R. J., Tripp, T. M., \& Kramer, R. M. 1997. At the breaking point: Cognitive and social dynamics of revenge in organizations. In R. Giacalone \& J. Greenberg (Eds.), Antisocial behavior in organizations: 18-36. Thousand Oaks, CA: Sage.

Boldizar, J. P., Perry, D. G., \& Perry, L. C. 1988. Gender and reward distributions: A test of two hypotheses. Sex Roles, 19: 569-579.

Breaugh, J., \& Starke, M. 2000. Research on employee recruitment: So many studies, so many remaining questions. Journal of Management, 26: 405-434.

Bridgeman, B. 1992. A comparison of quantitative questions in open-ended and multiple choice formats. Journal of Educational Measurement, 29: 253-271.

Brocker, J., \& Wiesenfeld, B. M. 1996. An integrative framework for explaining reactions to decisions: Interactive effects of outcomes and procedures. Psychological Bulletin, 120: 189-208.

Brockner, J., Tyler, T. R., \& Cooper-Schneider, R. 1992. The influence of prior commitment to an institution on reactions to perceived unfairness: The higher they are, the harder they fall. Administrative Science Quarterly, 37: 241-261.

Brutus, S., \& Ryan, A. M. 1998. Individual characteristics as determinants of the perceived job relatedness of selection procedures. Presented at $13^{\text {th }}$ Annual SIOP meeting, Dallas, TX.

Burke, M. J., Normand, J., \& Raju, N. S. 1987. Examinee attitudes toward computer-administered ability testing. Computers in Human Behavior, 3: 95-107.

Chan, D. 1997. Racial subgroup differences in predictive validity perceptions on personality and cognitive ability tests. Journal of Applied Psychology, 82: 311-320.

Chan, D., \& Schmitt, N. 1997. Video-based versus paper-and-pencil method of assessment in situational judgment tests: Subgroup differences in test performance and face validity perceptions. Journal of Applied Psychology, 82: 143-159.

Chan, D., Schmitt, N., DeShon, R. P., Clause, C. S., \& Delbridge, K. 1997. Reactions to cognitive ability tests: The relationships between race, test performance, face validity perceptions, and test-taking motivation. Journal of Applied Psychology, 82: 300-310.

Chan, D., Schmitt, N., Jennings, D., Clause, C. S., \& Delbridge, K. 1998a. Applicant perceptions of test fairness: Integrating justice and self-serving bias perspectives. International Journal of Selection and Assessment, 6: $232-239$.

Chan, D., Schmitt, N., Sacco, J. M., \& DeShon, R. P. 1998b. Understanding pretest and posttest reactions to cognitive ability and personality tests. Journal of Applied Psychology, 83: 471-485.

Cox, T. 1993. Cultural diversity in organizations. San Francisco: Berrett-Koehler.

Crant, J. M., \& Bateman, T. S. 1990. An experimental test of the impact of drug-testing programs on potential job applicants' attitudes and intentions. Journal of Applied Psychology, 75: 127-131.

Cunningham, M. R. 1989. Test-taking motivations and outcomes on a standardized measure of on-the-job integrity. Journal of Business and Psychology, 4: 119-127.

Feldman, J. M., \& Lynch, J. G. 1988. Self-generated validity and other effects of measurement on belief, attitude, intention, and behavior. Journal of Applied Psychology, 73: 421-435.

Fishbein, M., \& Ajzen, I. 1975. Belief, attitude, intentions and behavior: An introduction to theory and research. Boston, MA: Addison-Wesley.

Fiske, D. W. 1967. The subject reacts to tests. American Psychologist, 22: 287-296.

Fiske, S. T., \& Taylor, S. E. 1991. Social cognition. New York, NY: McGraw Hill.

Fredriksen, J. R., \& Collins, A. 1989. A systems approach to educational testing. Educational Researcher, 2: 27-32. 
jilliland, S. W. 1993. The perceived fairness of selection systems: An organizational justice perspective. Academy of Management Review, 18: 694-734.

Gilliland, S. W. 1994. Effects of procedural and distributive justice on reactions to a selection system. Journal of Applied Psychology, 79: 691-701.

Gilliland, S. W. 1995. Fairness from the applicant's perspective: Reactions to employee selection procedures. International Journal of Selection and Assessment, 3: 11-19.

Gilliland, S. W., Benson, L., \& Schepers, D. H. 1998. A rejection threshold in justice evaluations: Effects on judgment and decision-making. Organizational Behavior and Human Decision Processes, 76: 113-131.

Gilliland, S. W., \& Honig, H. 1994. Development of the selection fairness survey. Paper presented at the $9^{\text {th }}$ Annual Conference of the Society for Industrial and Organizational Psychology, Nashville, TN.

Gilliland, S. W., \& Steiner, D. D. 1999. Applicant reactions. In R. W. Eder \& M. M. Harris (Eds.), The employment interview handbook: 69-82. Thousand Oaks, CA: Sage.

Gist, M. E., \& Mitchell, T. R. 1992. Self-efficacy: A theoretical analysis of its determinants and malleability. Academy of Management Journal, 17: 183-211.

Greenberg, J. 1986. Determinants of perceived fairness of performance evaluations. Journal of Applied Psychology, 71: 340-342.

Greenberg, J. 1987. A taxonomy of organizational justice theories. Academy of Management Review, 12: 9-22.

Greenberg, J. 1988. Equity and workplace status: A field experiment. Journal of Applied Psychology, 73: $606-613$.

Greenberg, J. 1990. Employee theft as a reaction to underpayment inequity: The hidden cost of pay cuts. Journal of Applied Psychology, 75: 561-568.

Greenberg. J. 1994. Using socially fair treatment to promote acceptance of a work site smoking ban. Journal of Applied Psychology, 79: 288-297.

Greguras, G. J., \& Ryan, A. M. 1997. Test taker reactions, negative affectivity, and test performance. Presented at the twelfth annual meeting of the Society for Industrial and Organizational Psychology, St. Louis, MO.

Heider, F. 1958. The psychology of interpersonal relations. New York: Wiley.

Heilman, M. E., \& Herlihy, J. M. 1984. Affirmative action, negative reaction? Some moderating conditions. Organizational Behavior and Human Performance, 33: 204-213.

Heilman, M. E., Lucas, J. A., \& Kaplow, S. R. 1990. Self-derogating consequences of sex-based preferential selection: The moderating role of initial self-confidence. Organizational Behavior and Human Decision Processes, 46: 202-216.

Heilman, M. E., Rivero, J. C., \& Brett, J. F. 1991. Skirting the competency issue: Effects of sex-based preferential selection on task choices of men and women. Journal of Applied Psychology, 76: 99-105.

Heilman, M. E., Simon, M. C., \& Repper, D. P. 1987. Intentionally favored, unintentionally harmed?: The impact of sex-based preferential selection on self-perceptions and self-evaluations. Journal of Applied Psychology, 72: 62-68.

Herriot, P. 1989. Selection as a social process. In M. Smith \& I. T. Robertson (Eds.), Advances in selection and assessment: 171-187). London: John Wiley \& Sons.

Horvath, M., Ryan, A. M., \& Stierwalt, S. (in press). The influence of explanations for selection test use, outcome favorability and self-efficacy on test-taker perceptions. Organizational Behavior and Human Decision Processes.

Huo, Y. J., Smith, H. J., Tyler, T. R., \& Lind, E. A. 1996. Superordinate identification, subgroup identification, and justice concerns: Is separatism the problem; is assimilation the answer? Psychological Science, 7: 1-6.

Jackson, S. E., \& Associates. 1992. Diversity in the workplace: Human resources initiatives. New York: Guilford Press.

Kluger, A. N., \& Rothstein, H. R. 1993. The influence of selection test type on applicant reactions to employment testing. Journal of Business and Psychology, 8: 3-25.

Kohn, L. S., \& Dipboye, R. L. 1998. The effects of interview structure on recruiting outcomes. Journal of Applied Social Psychology, 28: 821-843.

Kravitz, D. A., Harrison, D. A., Turner, M. E., Levine, E. L., Chaves, W., Brannick, M. T., Denning, D. L., Russell, C. J., \& Conard, M. A. 1997. Affirmative Action: A review of psychological and behavioral research. Bowling Green, OH: The Society for Industrial \& Organizational Psychology.

Kravitz, D. A., Stinson, V., \& Chavez, T. L. 1994. Perceived fairness of tests used in making selection and promotion decisions. Presented at the annual meeting of the Society for Industrial and Organizational Psychology, Nashville, TN.

Krosnick, J. A., \& Petty, R. E. 1995. Attitude strength: An overview. In R. E. Petty \& J. A. Krosnick (Eds.), Attitude strength: Antecedents and consequences: 1-24. Mahwah, NJ: Erlbaum.

Latham, G. P., \& Finnegan, B. J. 1993. Perceived practicality of unstructured, patterned, and situational interviews. In H. Schuler, J. L. Farr, \& M. Smith (Eds.), Personnel selection and assessment: Individual and organizational perspectives: 41-55. Hillsdale, NJ: Erlbaum. 
Lemons, M. A., \& Danehower, V. C. 1997. Organizational justice in promotion decision for women: Contextual and cognitive determinants. Presented at Southern Management Association Meeting.

Liden, R. C., \& Parsons, C. K. 1986. A field study of job applicant interview perceptions, alternative opportunities, and demographic characteristics. Personnel Psychology, 39: 109-122.

Lind, E. A., \& Tyler, T. 1988. The social psychology of procedural justice. New York: Plenum.

Lounsbury, J. W., Bobrow, W., \& Jensen, J. B. 1989. Attitudes toward employment testing: Scale development, correlates, and "known-group" validation. Professional Psychology: Research and Practice, 20: 340-349.

Macan, T. H., Avedon, M. J., Paese, M., \& Smith, D. E. 1994. The effects of applicants' reactions to cognitive ability tests and an assessment center. Personnel Psychology, 47: 715-738.

Major, B., \& Deaux, K. 1982. Individual differences in justice behavior. In J. Greenberg \& R. L. Cohen (Eds.), Equity and justice in social behavior. New York: Academic Press.

Martin, C. L., \& Nagao, D. 1989. Some effects of computerized interviewing on job applicant responses. Journal of Applied Psychology, 74: 72-80.

McCulloch, M. C., \& Turban, D. B. 1997. Candidate and manager reactions to overt integrity tests. Presented at the $12^{\text {th }}$ annual conference of the Society for Industrial and Organizational Psychology, St. Louis, MO.

Mosier, C. I. 1947. A critical examination of the concept of face validity. Educational and Psychological Measurement, 7: 191-206.

Murphy, K. R., Thornton, G. C., \& Prue, K. 1991. Influence of job characteristics on the acceptability of employee drug testing. Journal of Applied Psychology, 76: 447-453.

Murphy, K. R., Thornton, G. C., \& Reynolds, D. H. 1990. College students' attitudes toward employee drug testing programs. Personnel Psychology, 43: 615-631.

Nassar, S. 1999. Jobless rate in the U.S. hits 29-year low. New York Times, April 3, C, 1.

Nevo, B. 1992. Examinee feedback: Practical guidelines. In M. Zeidner \& R. Most (Eds.), Psychological testing: An inside view: 377-398. Palo Alto: Consulting Psychologists Press.

Nevo, B. 1995. Examinee feedback questionnaire: Reliability and validity measures. Educational and Psychological Measurement, 55: 499-504.

Nield, A. F., \& Wintre, M. G. 1986. Multiple choice questions with an option to comment: Student attitudes and use. Teaching of Psychology, 13: 196-199.

Ployhart, R. E., \& Maynard, D. C. 1999. Broadening the scope of applicant reactions research: An exploratory investigation of the effects of job characteristics and level of competition. Paper presented at $14^{\text {th }}$ annual SIOP meeting, Atlanta, GA.

Ployhart, R. E., McFarland, L. A., \& Ryan, A. M. 1998, April. Applicant reactions to selection procedures: Expanding the justice framework. Presented at $13^{\text {th }}$ annual SIOP meeting, Dallas, TX.

Ployhart, R. E., \& Ryan, A. M. 1997. Toward an explanation of applicant reactions: An examination of organizational justice and attribution frameworks. Organizational Behavior and Human Decision Processes, 72: 308-335.

Ployhart, R. E., \& Ryan, A. M. 1998. Applicants' reactions to the fairness of selection procedures: The effects of positive rule violations and time of measurement. Journal of Applied Psychology, 83: 3-16.

Ployhart, R. E., Ryan, A. M., \& Bennett, M. 1999. Explanations for selection decisions: Applicants' reactions to informational and sensitivity features of explanations. Journal of Applied Psychology, 84: 87-106.

Powell, G. N. 1991. Applicant reactions to the initial employment interview: Exploring theoretical and methodological issues. Personnel Psychology, 44: 67-83.

Robertson, I. T., Iles, P. A., Gratton, L., \& Sharpley, D. 1991. The impact of personnel selection and assessment methods on candidates. Human Relations, 44: 963-982.

Rosse, J. G., Miller, J. L., \& Stecher, M. D. 1994. A field study of job applicants' reactions to personality and cognitive ability testing. Journal of Applied Psychology, 79: 987-992.

Ryan, A. M., \& Chan, D. 1999a. Perceptions of the EPPP: How do licensure candidates view the process? Professional Psychology, 30: 519-530.

Ryan, A. M., \& Chan, D. 1999b. Self-serving biases in perceptions of fairness and the psychology licensing examination. Paper presented at the $14^{\text {th }}$ annual conference of the Society for Industrial and Organizational Psychology, Atlanta, GA.

Ryan, A. M., \& Greguras, G. 1998. Life is not multiple choice: Reactions to the alternatives. In M. D. Hakel (Ed.), Beyond multiple choice: Alternatives to traditional assessment: 183-202. Mahwah, NJ: Lawrence Erlbaum.

Ryan, A. M., Greguras, G. J., \& Ployhart, R. E. 1996. Perceived job relatedness of physical ability testing for firefighters: Exploring variations in reactions. Human Performance, 9: 219-240.

Ryan, A. M., \& McFarland, L. A. 1997a. Influences on applicant withdrawal from selection processes. Presented at the twelfth annual meeting of the Society for Industrial and Organizational Psychology, St. Louis, MO.

Ryan, A. M., \& McFarland, L. A. 1997b. Perceived job relatedness as a moderator of the validity of cognitive ability and biodata instruments. Presented at Academy of Management Conference, Boston, MA. 
Ryan, A. M., Ployhart, R. E., Greguras, G. J., \& Schmit, M. J. 1997. Predicting applicant withdrawal form applicant attitudes. Presented at the twelfth annual meeting of the Society for Industrial and Organizational Psychology, St. Louis, MO.

Ryan, A. M., Ployhart, R. E., Greguras, G. J., \& Schmit, M. J. 1998. Test preparation programs in selection contexts: Self-selection and program effectiveness. Personnel Psychology, 51: 599-622.

Ryan, A. M., Sacco, J. M., McFarland, L. A., \& Kriska, S. D. 2000. Applicant self-selection: Correlates of withdrawal from a multiple hurdle process. Journal of Applied Psychology, 85: 163-179.

Ryan, A. M., \& Sackett, P. R. 1987. Pre-employment honesty testing: Fakability, reactions of test takers, and company image. Journal of Business and Psychology, 1(3): 248-256.

Rynes, S. L. 1991. Recruitment, job choice, and post-hire consequences: A call for new research directions. In M. D. Dunnette \& L. M. Hough (Eds.), Handbook of industrial and organizational psychology, Vol. 2: 399-444. Palo Alto: Consulting Psychologists Press $2^{\text {nd }}$ ed.

Rynes, S. L. 1993. Who's selecting whom? Effects of selection practices on applicant attitudes and behavior. In. N. Schmitt \& W. C. Borman (Eds.), Personnel selection in organizations: 240-274. San Francisco: Jossey-Bass.

Rynes, S. L., \& Connerley, M. R. 1993. Applicant reactions to alternative selection procedures. Journal of Business and Psychology, 7: 261-277.

Saks, A. M., Leck, J. D., \& Saunders, D. M. 1995. Effects of application blanks and employment equity on applicant reactions and job pursuit intentions. Journal of Organizational Behavior, 16: 415-430.

Sarason, I. G., Pierce, G. R., \& Sarason, B. R. 1996. Cognitive interference: Theories, methods, and findings. Mahwah, NJ: Erlbaum.

Schmit, M. J., \& Ryan, A. M. 1992. Test-taking dispositions: A missing link? Journal of Applied Psychology, 77: $629-637$.

Schmit, M. J., \& Ryan, A. M. 1997. Applicant withdrawal: The role of test-taking attitudes and racial differences. Personnel Psychology, 50: 855-876.

Schmitt, N., \& Gilliland, S. W. 1992. Beyond differential prediction: Fairness in selection. In D. M. Saunders (Ed.), New approaches to employee management: Fairness in employee selection, Vol. 1: 21-46. Greenwich, CT: JAI Press.

Schuler, H. 1993. Social validity of selection situations: A concept and some empirical results. In H. Schuler, J. L. Farr, \& M. Smith (Eds.), Personnel selection and assessment: Individual and organizational perspectives: 11-26. Hillsdale, NJ: Erlbaum.

Shotland, A. B., \& Alliger, G. M. 1999. The advantages of employing a face valid, multimedia selection device: Comparison of three measures. Presented at the $14^{\text {th }}$ Annual Conference of the Society for Industrial and Organizational Psychology, Atlanta, GA.

Singer, M. 1990. Determinants of perceived fairness in selection practices: An organizational justice perspective. Genetic, Social and General Psychology Monographs, 116: 477-494.

Smither, J. W., Reilly, R. R., Millsap, R. E., Pearlman, K., \& Stoffey, R. W. 1993. Applicant reactions to selection procedures. Personnel Psychology, 46: 49-76.

Steele, C. M., \& Aronson, J. 1995. Stereotype threat and the intellectual test performance of African Americans. Journal of Personality and Social Psychology, 69: 797-811.

Steiner, D., \& Gilliland, S. W. 1996. Fairness reactions to personnel selection techniques in France and the United States. Journal of Applied Psychology, 81: 134-141.

Thorsteinson, T. J., \& Ryan, A. M. 1997. The effect of selection ratio on perceptions of the fairness of a selection test battery. International Journal of Selection and Assessment, 5: 159-168.

Turner, M. E., \& Pratkanis, A. R. 1994. Affirmative action as help: A review of recipient reactions to preferential selection and affirmative action. Basic and Applied Social Psychology, 15: 43-69.

Truxillo, D. M., \& Bauer, T. N. 1999. Applicant reactions to test score banding in entry-level and promotional contexts. Journal of Applied Psychology, 84: 322-339.

Tyler, T. R., \& Dawes, R. 1993. Fairness in groups: Comparing the self-interest and social identity perspectives. In B. Mellers \& J. Baron (Eds.), Psychological perspectives on justice; Theory and applications: 87-108. Cambridge: Cambridge University Press.

Tyler, T. R., \& Degoey, P. 1995. Collective restraint in social dilemmas: Procedural justice and social identification effects on support for authorities. Journal of Personality and Social Psychology, 69: $482-497$.

Weiner, B. 1985. An attributional theory of achievement motivation and emotion. Psychological Review, 92 : 548-573.

Weiner, B. 1986. An attributional theory of motivation and emotion. New York, NY: Springer-Verlag.

Whitney, D. J., Diaz, J., Minneghino, M. E., \& Powers, K. T. 1998. Test-taker perceptions of overt and personality-based integrity inventories. Presented at the $13^{\text {th }}$ annual conference for Industrial and Organizational Psychology. 
Copyright of Journal of Management is the property of Elsevier Science Publishing Company, Inc. and its content may not be copied or emailed to multiple sites or posted to a listserv without the copyright holder's express written permission. However, users may print, download, or email articles for individual use. 